US Army Corps

of Engineers $S_{\circledast}$

Engineer Research and

Development Center

\title{
Loose-Surface Tire-Terrain Interaction During High-Speed Maneuvers
}

Nicole L. Buck, Barry A. Coutermarsh, and Sally A. Shoop

November 2010 



\section{Loose-Surface Tire-Terrain Interaction During High-Speed Maneuvers}

Nicole L. Buck, Barry A. Coutermarsh, and Sally A. Shoop

Cold Regions Research and Engineering Research Laboratory

U.S. Army Engineer Research and Development Center

72 Lyme Road

Hanover, NH 03755-1290

Final Report

Approved for public release; distribution is unlimited.

Prepared for Headquarters, U.S. Army Corps of Engineers

Washington, DC 20314-1000 


\begin{abstract}
For many years, rally-car drivers have been training military Special Forces in driving techniques that allow them to maintain high speeds on loose surfaces. The Cold Regions Research and Engineering Laboratory has been working with rally-car drivers to gain a more complete understanding of their driving techniques and their knowledge of driving on loose surfaces. A more complete understanding of the interaction of the tire-surface interface is also needed. This study was designed to quantify anecdotal descriptions of dynamic changes in the road surface as a result of successive high-speed maneuvers on a loosesurface roadway. The two primary maneuvers tested both involve a controlled skid on unpaved surfaces: the straight-line brake and highspeed hard turn. Multiple tests of each maneuver were completed over the same section of roadway on two different types of loose surface. Test observations showed that, as a vehicle traverses a section of roadway in a controlled skid, the tires remove loose material and transport the material to a new location; thereby changing the tractive characteristics of the roadway. This change is amplified as successive vehicles traverse the same path. A significant increase in the surface traction coefficient is observed where material has been removed from the original surface, and a decrease in surface traction is observed where loose material has built up on the original surface.
\end{abstract}

DISCLAIMER: The contents of this report are not to be used for advertising, publication, or promotional purposes. Citation of trade names does not constitute an official endorsement or approval of the use of such commercial products. All product names and trademarks cited are the property of their respective owners. The findings of this report are not to be construed as an official Department of the Army position unless so designated by other authorized documents.

DESTROY THIS REPORT WHEN NO LONGER NEEDED. DO NOT RETURN IT TO THE ORIGINATOR. 


\section{Table of Contents}

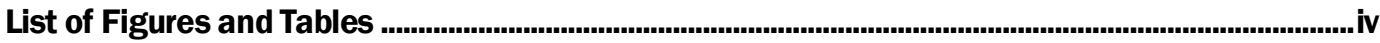

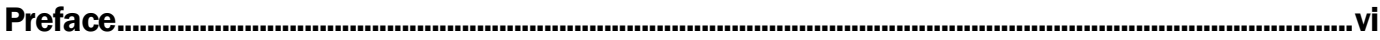

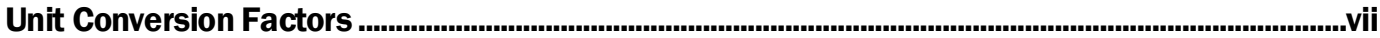

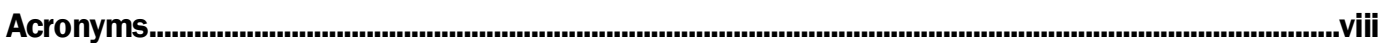

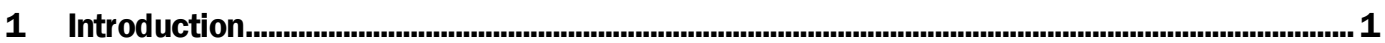

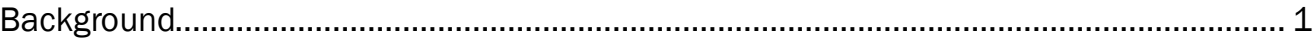

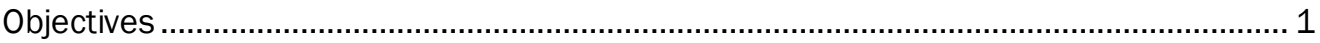

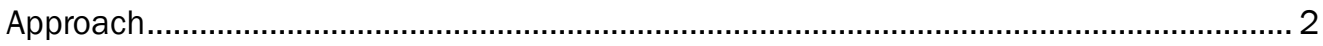

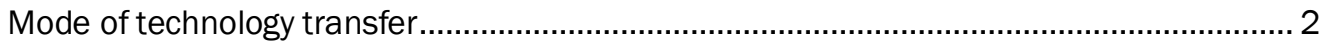

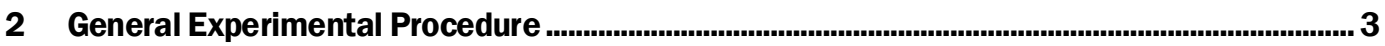

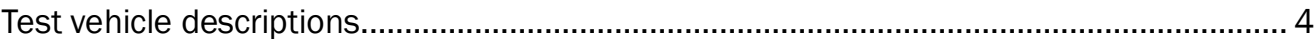

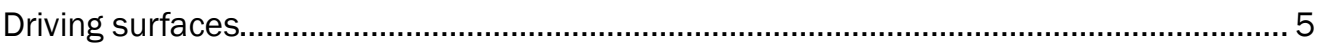

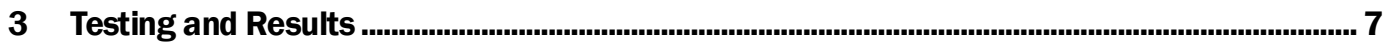

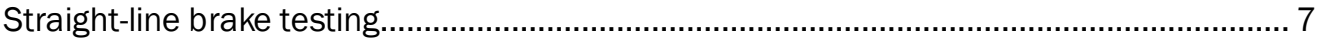

Team O'Neil Proof of Concept Tests (5 May 2009) ................................................................. 7

Team O'Neil Tests (29 June 2009)...................................................................................... 9

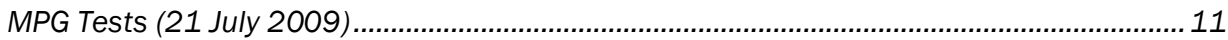

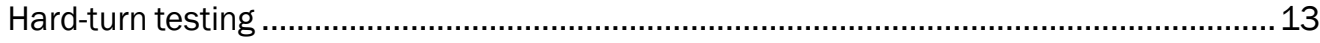

Team O'Neil Proof of Concept (5 May 2009) .......................................................................13

Team O'Neil Tests (29 June 2009)................................................................................ 14

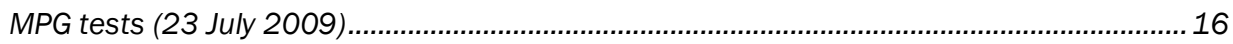

Degraded surface traction tests................................................................................ 17

4 Discussion ..............................................................................................................19

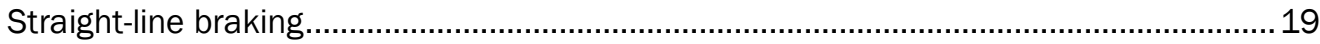

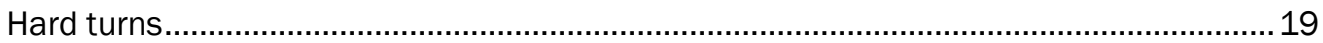

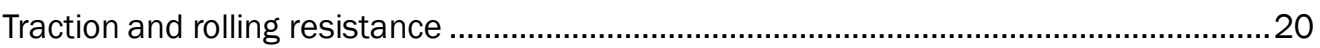

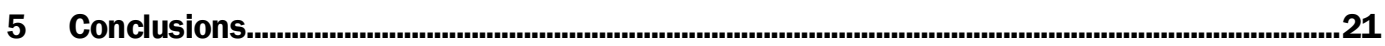

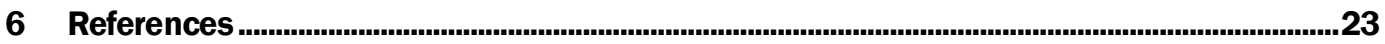

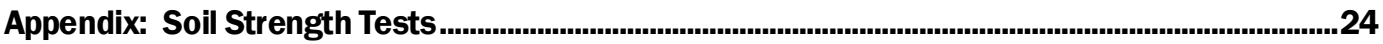

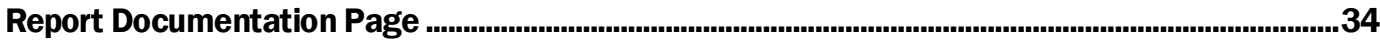




\section{List of Figures and Tables}

\section{Figures}

Figure 1. Team O'Neil and MPG driving surfaces

Figure 2. First SLB with Ford Focus at Team O'Neil - Material pushed forward and piled below base of front tire

Figure 3. Second SLB test with Ford Focus at Team O'Neil - Red Chalk from the deeper layers is visible behind rear tire after a second SLB test in the same vehicle path.

Figure 4. CIV at the entrance to the braking section

Figure 5. Material buildup in front of front tires and rut depth measurements .

Figure 6. Straight-line braking results at Team O'Neil showing on average increasing longitudinal traction and rut depths

Figure 7. Straight-line braking tests at MPG showing the surface marking, typical spray pattern, and rut wall angles

Figure 8. MPG SLB: Longitudinal traction coefficient for the CIV (left) and longitudinal acceleration for the Focus (right), both showing a general trend towards increasing surface traction over successive tests.

Figure 9. Hard turn tests performed at Team O'Neil under dry conditions showing fine particle spray from the upper surface (left) and excavation down to a depth of 2.5 to $4 \mathrm{~cm}$ indicated by exposed red chalk(right)

Figure 10. Hard-turn tests at Team O'Neil showing coarse material spray (left), fold-over surface material (center), and gradation in the throw height of course through fine material (right)

Figure 11. MPG hard-turn tests showing the CIV traveling through the painted section (left), the Explorer traveling through a marked section to determine direction of particle throw (center), and particles thrown to the outside of the corner as a result of drifting through the section with a meter stick (right)

Figure 12. Lateral traction coefficient and lateral acceleration for hard-turn tests in the CIV at MPG shows no distinct trend in either traction or lateral acceleration through successive runs in a similar path

Figure 13. Longitudinal traction coefficient for a normal driving surface, loose surface (a surface of loose material pushed to the side as a result of maneuvers), and competent surface.

Figure A1. DCP Profiles for Team O'Neil, 29 June 2009.......................................................................25

Figure A2. Loadman data for Team O'Neil, 29 June 2009 ..................................................................26

Figure A3. Grain size analysis for Team O'Neil, 29 June 2009..............................................................29

Figure A4. GPS locations of the four corners of the testing area and the locations of

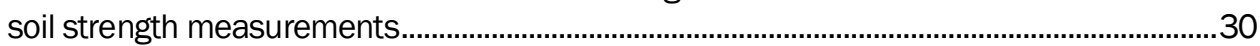

Figure A5. DCP data from Romeo, Ml, 20 July 2009............................................................................31

Figure A6. Loadman data for Romeo, Ml, 20 July 2009......................................................................32 


\section{Tables}

Table 1. Surface properties at test locations................................................................................... 6

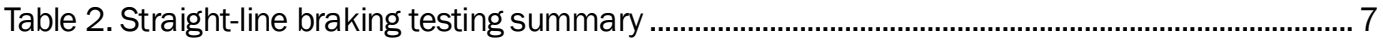

Table 3. Braking longitudinal traction coefficient for Team O'Neil ........................................................10

Table 4. CIV straight-line braking results from MPG ..........................................................................12

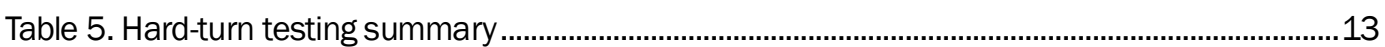

Table 6. Explorer results from Team O'Neil hard-turn tests ...................................................................15

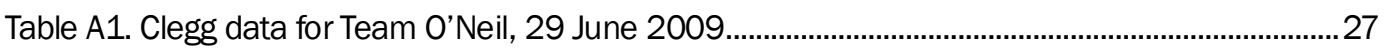

Table A2. Clegg data from Romeo, MI, 20 July 2009 ……...................................................................33 


\section{Preface}

Support and funding for this report was provided by Department of Defense Army Research, Development, Testing, and Evaluation funds under Military Engineering Advances Technology. The work was performed by Nicole L. Buck, Barry A. Coutermarsh, and Sally A. Shoop of the Force Projection and Sustainment Branch (RR-H), Cold Regions Research and Engineering Laboratory (CRREL). Technical support was provided by Charles Smith and Chris Berini, Engineering Resources Branch, CRREL.

This study was completed under the general supervision of J ames Buska, Chief, RR-H, and Dr. J ustin Berman, Chief, Research and Engineering Division. The Acting Technical Director for Terrestrial and Geospatial Sciences was J ohn Zufelt. Deputy Director of CRREL was Dr. Lance Hansen and the Director was Dr. Robert E. Davis.

CRREL is an element of the U.S. Army Engineer Research and Development Center (ERDC), U.S. Army Corps of Engineers. The Commander and Executive Director of ERDC is COL Kevin J. Wilson, and the Director of ERDC is Dr. J effery P. Holland. 


\section{Unit Conversion Factors}

\begin{tabular}{|l|c|l|}
\hline Multiply & By & To Obtain \\
\hline degrees (angle) & 0.01745329 & radians \\
\hline feet & 0.3048 & meters \\
\hline gallons (U.S. liquid) & $3.785412 \mathrm{E}-03$ & cubic meters \\
\hline Inches & 25.4 & millimeters \\
\hline miles per hour & 0.44704 & meters per second \\
\hline pounds (force) per square inch & 6.894757 & kilopascals \\
\hline yards & 0.9144 & meters \\
\hline
\end{tabular}




\section{Acronyms}

$\begin{array}{ll}\text { 4WD } & \text { four wheel drive } \\ \text { AWD } & \text { all wheel drive } \\ \text { ADMA } & \text { Automotive Dynamic Motion Analyzer } \\ \text { CAN } & \text { controller area network } \\ \text { CBR } & \text { California bearing ratio } \\ \text { CIH } & \text { Clegg Impact Hammer } \\ \text { CIHL } & \text { Clegg Impact Hammer, Light Weight } \\ \text { CIV } & \text { CRREL Instrumented Vehicle (main text) } \\ \text { CIV } & \text { Clegg Impact Value (appendix) } \\ \text { CRREL } & \text { Cold Regions Research and Engineering Laboratory } \\ \text { DCP } & \text { dynamic cone penetrometer } \\ \text { E modulus } & \text { elastic modulus } \\ \text { FWD } & \text { front wheel drive } \\ \text { G } & \text { acceleration normalized by gravity } \\ \text { kph } & \text { kilometers per hour } \\ \text { MPa } & \text { megapascals } \\ \text { MPG } & \text { Michigan Proving Grounds } \\ \text { RWD } & \text { rear wheel drive } \\ \text { SLB } & \text { straight-line brake }\end{array}$




\section{Introduction}

\section{Background}

Military operations are frequently performed on unimproved loose-surface gravel roadways. Understanding high-speed, loose-surface vehicle-terrain dynamics can improve vehicle handling and thus the safety of soldiers during vehicle maneuvers. To provide a more comprehensive understanding of loose material and its impact on vehicle dynamics, the Cold Regions Research and Engineering Laboratory (CRREL) has teamed with loosesurface driving experts - rally car drivers - to investigate high-speed offroad driving dynamics (Coutermarsh and Shoop 2009; Shoop et al. 2010). Furthermore, rally-car driving techniques have been employed for many years in teaching Special Forces how to maintain vehicle control during high-speed operations.

One of the fundamental techniques of maneuvering a vehicle at high-speed on loose surfaces is to induce a controlled skid or to drift across the surface. Through drifting, the vehicle operator is able to control the vehicle while maintaining a high rate of speed. These high-speed driving techniques can have significant impacts on the driving surface. Rally-car drivers describe having to quickly read the driving surface as they observe areas of loose material building up on the road surface after material is scraped off the driving path through successive passes of vehicles at highspeeds. They note poor traction in the loose areas and better traction in the traveled path. The purpose of our study is to quantify rally-car driver's anecdotal descriptions of the driving surface by measuring the impacts of high-speed maneuvers on loose surfaces and, specifically, address how these maneuvers alter vehicle traction on the roadway.

\section{Objectives}

The primary objective of this study was to expand our understanding of vehicle-terrain dynamics to enhance operator awareness and improve the safety and efficiency of the mission. This study is part of a larger project to develop a low cost, motion-based vehicle simulator designed to teach and maintain the rally-car style driving skills taught to our troops. The simulator is not designed to capture all of the vehicle-terrain dynamics, but to realistically impart the feeling of driving at high speeds on loose surfaces. 
Results of this study will eventually be incorporated into the simulator to dynamically alter the roadway as simulated vehicles follow the same route.

\section{Approach}

The experiments were designed to capture vehicle-terrain interaction on two different types of loose surfaces: (1) a hard-packed gravel with a wide range of material sizes and (2) a looser uniformly sized pea-gravel. Two rally-car maneuvers, straight-line brake (SLB) and hard turn with drift, were chosen for study. These maneuvers are two of the simpler maneuvers to replicate. The driving surface was marked with paint, chalk, or colored sand to track particle motion. Simultaneous observations of tire forces during the vehicle maneuvers and particle motion were used to help determine the deformation of the loose surface during high-speed maneuvers performed by professional rally-car drivers.

\section{Mode of technology transfer}

This report will be made accessible through the World Wide Web (WWW) at URL: 


\section{General Experimental Procedure}

Common rally-car maneuvers such as the pendulum turn or trail brake alter the characteristics of the driving surface, which in turn will change the way the rally driver chooses to operate. Since it is difficult to replicate a pendulum turn or trail brake multiple times in a specific location, the two simpler maneuvers, SLB and hard turn with drift, are studied. Straightline braking and hard-turn tests were performed by professional rally-car drivers in three instrumented test vehicles. The driving surface was marked with paint, chalk, or colored sand to track particle motion. Simultaneous observations of tire forces and particle motion are used to lend insight into the deformation of the loose surface during these high-speed maneuvers. The specific experimental procedure for each set of tests is described in Chapter 3, Testing and Results.

A vehicle's response to alterations in the road surface can be captured through measurements of the vehicle's tractive force or through the vehicle's resistance to rolling. Traction on unimproved loose-surface roadways can be highly variable and is influenced by the terrain, roadway usage, and surface material. The traction coefficient $\left(\mathrm{TR}_{c}\right)$ non-

dimensionally describes the longitudinal tractive force available and is calculated by:

$$
T R_{c}=F_{l} / F_{v}
$$

where $F_{l}$ is the longitudinal force and $F_{v}$ is the vertical force at the contact patch.

The lateral coefficient $\left(\mathrm{L}_{c}\right)$ non-dimensionally describes the lateral tractive force that develops at the contact patch. The lateral coefficient is calculated by:

$$
L_{c}=F_{t} / F_{v}
$$

where $\mathrm{F}_{t}$ is the lateral force. 
The rolling resistance $\left(R R_{c}\right)$ is the vehicle's resistance to longitudinal motion and is calculated as follows:

$$
R R_{c}=F_{l} / F_{v}
$$

where $F_{l}$ is the longitudinal force and $F_{v}$ is the vertical force at the contact patch.

These three parameters describe the interaction between the tire and surface and are used throughout this study to assess the impact of high-speed maneuvers on loose surfaces. The coefficients are influenced by the surface conditions, the tire's slip and slip angle at the contact patch, and whether the tire is free rolling or locked. When forces at the contact patch are not available, the longitudinal and lateral accelerations of the vehicle sprung mass are used as a proxy for the traction and lateral coefficients, respectively.

\section{Test vehicle descriptions}

Three vehicles were used during the testing procedures: a 1977 J eep Cherokee Chief - the CRREL Instrumented Vehicle (CIV) - a 2008 Ford Focus, and a 2008 Ford Explorer. The CIV is capable of various mobility tests including traction, rolling resistance, and maneuverability. One of the primary advantages of the CIV for mobility testing is the ability to measure longitudinal, lateral, and vertical forces at all four tire-surface interfaces. Other advantages of the CIV are the ability to switch into four wheel, front wheel, and rear wheel drive(4WD, FWD, RWD) and the ability to turn off either the front or rear brakes. In addition to these unique features, instrumentation on the CIV also measures four independent wheel speeds, the vehicle speed via a $5^{\text {th }}$ wheel or optical speed sensor, tri-axial vehicle accelerations and angular rates, the location of the vehicle (based on the Global Positioning System [GPS]), and driver inputs such as brake force, steering angle, and throttle position. These options make the CIV capable of performing a wide range of mobility tests. More information on the instrumentation of the CIV can be found in Blaisdell (1983) and Coutermarsh and Shoop (2008). The majority of experiments described below were conducted with the CIV since it was the only vehicle capable of measuring forces at the tire-surface interface. 
The 2008 Ford Focus and Explorer have three primary measurement systems: an Automotive Dynamic Motion Analyzer (ADMA), on-board controller area network (CAN) channels, and additional analog channels. The ADMA, which is attached in the vehicle's sprung mass, tracks the vehicles location via GPS, measures tri-axial accelerations, and measures key rotational parameters (roll, pitch, and yaw). Tapping into the vehicles onboard CAN system provides vehicle and wheel speeds, engine metrics, and throttle inputs. Additional analog measurements record brake inputs, suspension travel, steering, and transverse and longitudinal speed with the Corrsys S400 optical speed sensor. Through these three measurement systems, driver inputs can be directly related to vehicle response as discussed further in Shoop et al. (2010). Additionally, the Explorer has the capability to switch between RWD and all wheel drive (AWD).

\section{Driving surfaces}

Experiments were performed at two locations: Team O'Neil Rally School in Dalton, NH and Ford's Michigan Proving Grounds (MPG) in Romeo, MI. The Team O'Neil surface is a well-graded angular crushed gravel surface referred to as hard-pack. The MPG surface is 0.64-centimeter $(\mathrm{cm})$ diameter pea stone over recycled asphalt. At both sites, extensive surface characterizations were conducted prior to testing, including strength and elasticity measurements. The bearing capacity is reported in terms of the California bearing ratio (CBR) and is a measure of the ability of a surface to support loads applied to the ground. The CBR for the Team O'Neil and MPG surfaces were both greater than $100 \%$ for all testing days as measured by a dynamic cone penetrometer. A CBR of $100 \%$ is equivalent to a crushed limestone gravel surface. The elastic (E) modulus is a measure of the stiffness of the material in response to loading. The E modulus for the upper $152 \mathrm{~mm}$ (6 in.) of the Team O'Neil surface under completely saturated conditions was 65 megapascals (MPa). The E modulus for the upper $152 \mathrm{~mm}$ (6 in.) of the MPG surface, including the pea-stone surface, was $125 \mathrm{MPa}$ and the lower recycled asphalt surface was $99 \mathrm{MPa}$ after the pea stone was scraped away by hand. The surface strength measurements for the two sites confirm that they have hard surfaces that are resistant to deformation under normal loading conditions. Additional information on the surface characterizations for the sites can be found in the Appendix. The surfaces are shown in Figure 1. Table 1 summarizes the surface properties. 


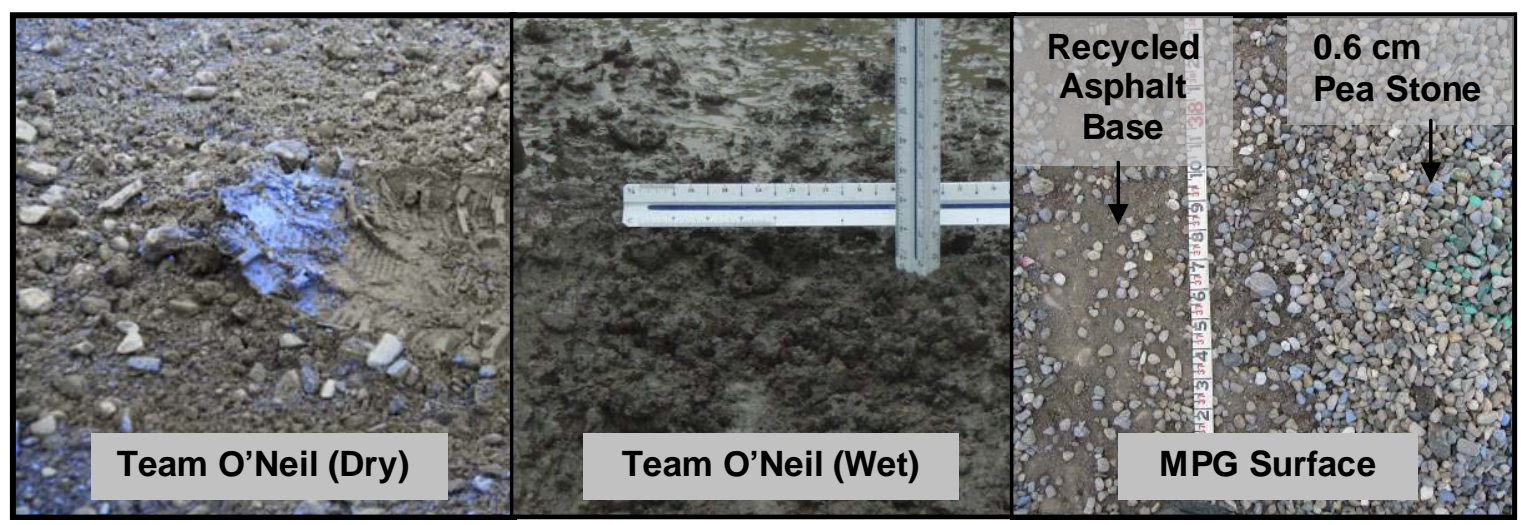

Figure 1. Team O'Neil and MPG driving surfaces.

Table 1. Surface properties at test locations.

\begin{tabular}{|l|l|l|l|l|l|}
\hline Date & Location & $\begin{array}{l}\text { CBR } \\
\text { DCP }\end{array}$ & $\begin{array}{l}\text { CBR } \\
\text { Clegg }\end{array}$ & $\begin{array}{l}\text { E } \\
\text { (MPa) }\end{array}$ & $\begin{array}{l}\text { USCS Class Grain } \\
\text { Sizing }\end{array}$ \\
\hline 29 June 2009 & $\begin{array}{l}\text { Team O'Neil - } \\
\text { Wet }\end{array}$ & 100 & 45 & 65 & $\begin{array}{l}\text { Silty Sand } \\
\text { (SM) }\end{array}$ \\
\hline 20 July 2009 & $\begin{array}{l}\text { MPG Pea } \\
\text { Stone }\end{array}$ & - & 13 & 125 & $\begin{array}{l}\text { Well Graded Gravel } \\
\text { (GW) }\end{array}$ \\
\hline 20 July 2009 & $\begin{array}{l}\text { MPG Sub- } \\
\text { strate }\end{array}$ & 100 & 113 & 99 & $\begin{array}{l}\text { Recycled Asphalt } \\
\text { (not sized) }\end{array}$ \\
\hline
\end{tabular}

Because of its instrumentation, the CIV allows for unique ways of testing the in-situ longitudinal and lateral surface traction coefficients as well as rolling resistance. The longitudinal surface traction coefficient is measured by driving with the front tires while the vehicle is being braked by the freewheeling rear tires (driving traction). The lateral surface traction coefficient is measured by briefly connecting the CIV to a tow rig and pulling the CIV longitudinally while turning the tires to induce a lateral resisting force (Shoop and Coutermarsh 2006). The rolling resistance is measured by free-wheeling the front tires and driving the rear tires.

The longitudinal traction coefficient measured on the day of testing prior to conducting tests was on average $0.86,0.60$, and 0.65 for Team O'Neil (dry), Team O'Neil (wet), and the MPG surface including pea stone, respectively. The maximum lateral traction coefficient for both Team O'Neil (wet) and MPG was 0.55 (Coutermarsh and Shoop 2010). The rolling resistance measured on the day of testing was 0.016 and 0.018 for Team O'Neil (dry) and MPG, respectively. Rolling resistances were not obtained at Team O’Neil during wet conditions. 


\section{Testing and Results}

\section{Straight-line brake testing}

The SLB test involves braking the vehicle hard at a specified position from approximately 48 kilometers per hour (kph). For each series of tests, the surface is marked with a combination of colored chalk, spray-paint, and/ or colored sand to observe particle motion. Three series of SLB tests were conducted: (1) an initial proof of concept at Team O'Neil under dry conditions, (2) a series of tests at Team O'Neil under very wet conditions with a saturated surface, and (3) a series of tests at MPG under damp conditions. Table 2 summarizes the various test conditions.

Table 2. Straight-line braking testing summary.

\begin{tabular}{|l|l|l|l|l|}
\hline Date & Location & Test & Vehicle & $\begin{array}{l}\text { Surface } \\
\text { Condition }\end{array}$ \\
\hline 5 May 2009 & Team O'Neil & SLB from 48 kph & Focus & Dry \\
\hline 29 June 2009 & Team O'Neil & SLB from 48 kph & CIV & Wet \\
\hline 21 July 2009 & MPG & SLB from 48 kph & Focus and CIV & Damp \\
\hline
\end{tabular}

\section{Team 0'Neil proof of concept tests (5 May 2009)}

An initial proof of concept series of tests was performed at Team O'Neil to develop a methodology for assessing dynamic changes in the unpaved road surface as a result of rally-style maneuvers. A 0.6 meter $(\mathrm{m})$ by $1.8 \mathrm{~m} \mathrm{sec}-$ tion of gravel surface was excavated down 2.5 to $4 \mathrm{~cm}$ where a thin layer of red chalk was placed in the excavation. The excavated material was replaced, compacted, and covered with a thin layer of blue chalk. A short series of tests were conducted under dry conditions to validate the experimental procedure. A successful SLB test was conducted when the front tire stopped near the end of the colored patch. The tests were conducted using the Ford Focus, which was not yet fully instrumented. While this test was originally intended as a proof of concept, weather and surface conditions prevented running another similar series of tests with the fully instrumented vehicle. Thus the results of this proof of concept test are presented. 
Weather conditions for the proof of concept tests were dry and clear. The Ford Focus accelerated to a speed of approximately $48 \mathrm{kph}$ and successfully stopped within the multi-layered chalked surface. The blue chalked surface material was pushed forward in front of the front tire and a small patch of red chalked material was visible at the base of the tire path. Finer material was pushed forward and to the side of the test patch up to approximately $0.6 \mathrm{~m}$. Courser material was pushed forward and to the side up to approximately $15 \mathrm{~cm}$ with some piling up beneath the front of the tire. Figure 2 shows the results of this first test.

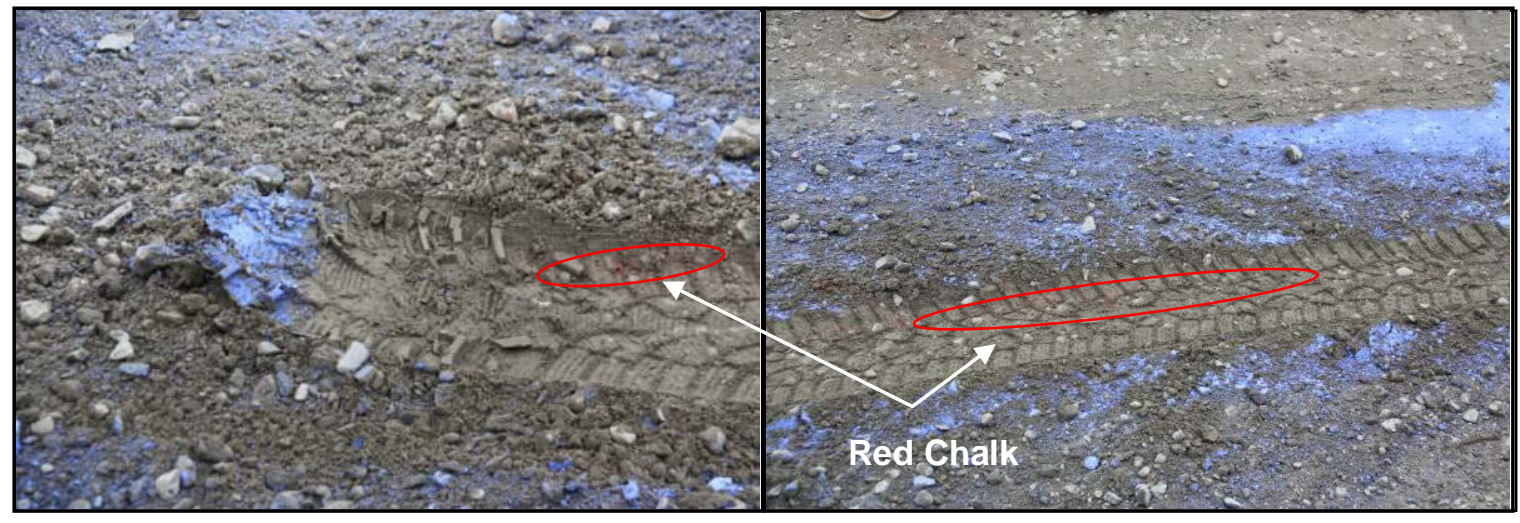

Figure 2. First SLB with Ford Focus at Team O'Neil - Material pushed forward and piled below base of front tire (left) and a small amount of lower red chalk appearing in tire track (right).

A second SLB test was performed in the same chalk patch within the same track. Additional material was excavated approximately 2.5 to $4 \mathrm{~cm}$ and pushed forward or to the side by the front and rear tires exposing a larger section of the red chalk layer. Figure 3 shows the results of the second test.

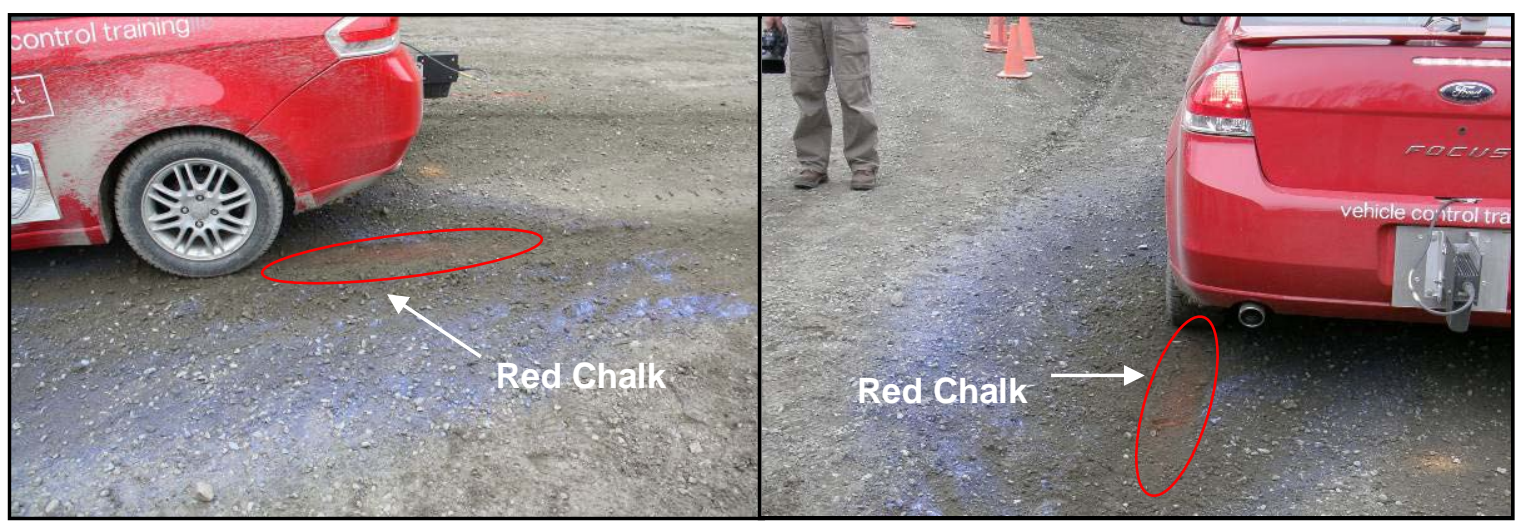

Figure 3. Second SLB test with Ford Focus at Team O'Neil - Red Chalk from the deeper layers is visible behind rear tire after a second SLB test in the same vehicle path. 


\section{Team 0'Neil tests (29 June 2009)}

A second series of SLB tests were performed at Team O'Neil under dramatically different weather conditions using the CIV (Figure 4). On the day of testing, over $3.3 \mathrm{~cm}$ of rain fell at the St. J ohnsbury, VT rain gage (NCDC 2010) located approximately $24 \mathrm{~km}$ from the testing site. Spray paint, chalk, and sand were applied to the gravel surface; however, most of the material was washed away by the rain before test results could be recorded. During this day of testing, material motion was tracked by photography, and video and rut depths were measured. Chalk layering experiments similar to the proof of concept were not conducted due to weather conditions.

On this date, the CIV was used in nine SLB tests conducted in three sets: the first set was in FWD, the second set in RWD, and the third set in 4WD. Each set of tests consisted of three tests following the same vehicle path at the same speed (48 kph) in order to track surface development over multiple tests. Particles were pushed forward and to the side as a slurry due to the excessive moisture content of the surface material. Typically, approximately $2 \mathrm{~cm}$ of material built up in front of the front tires as a result of the tire "plowing" across the loose surface (Figure 5, left). The amount of material buildup in front of the front tires did not change significantly through the testing. Due to conditions, it was difficult to measure the distance that material was thrown from the vehicle path.

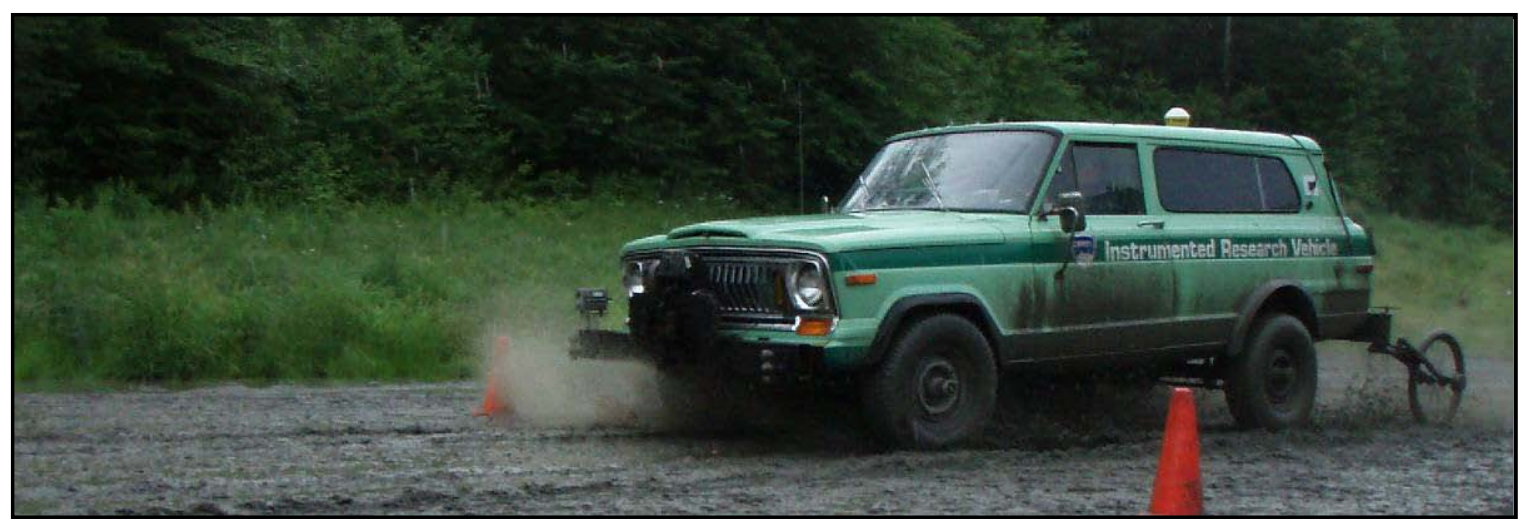

Figure 4. CIV at the entrance to the braking section. 


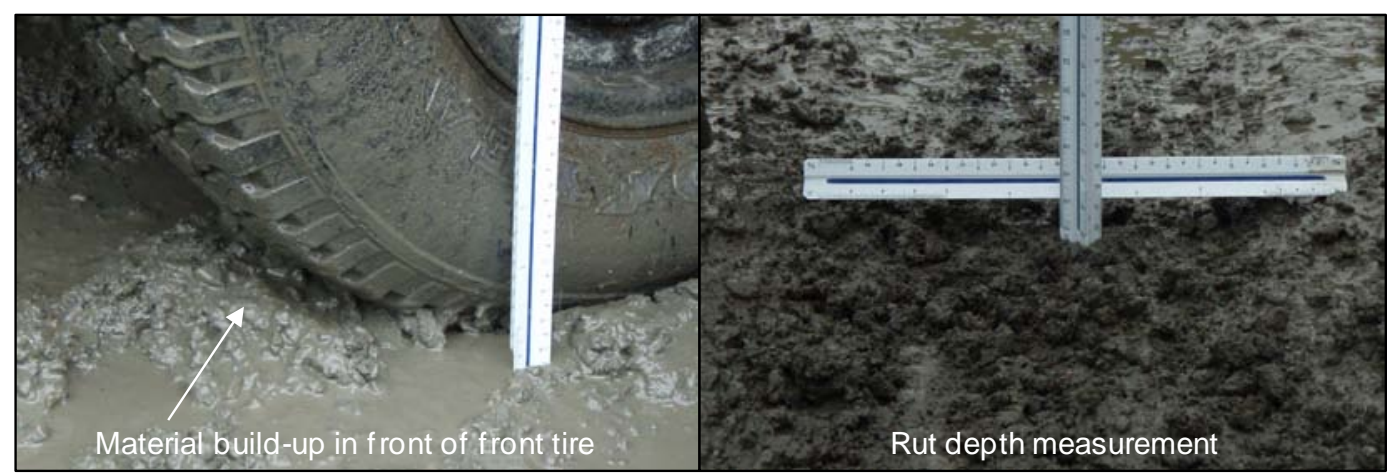

Figure 5. Material buildup in front of front tires and rut depth measurements.

Using load cell data from the CIV, the tire traction coefficient could be measured during each of these tests. On average, the first test of each set had a significantly lower longitudinal traction coefficient than the successive two tests.

Table 3 and Figure 6 show the average longitudinal traction coefficient for the front wheels for the test within each set of three tests (i.e., Test 1 is the average of the first SLB test for each of the three test sets described above). Error bars represent the standard error between each set of tests.

To assess the impact of the maneuver on the surface, the rut depth for each test was measured. The ruts were measured from the top of the rut to the base of the rut in a location approximately $3 \mathrm{~m}$ behind the vehicle. Similar to the traction coefficient, the rut depth increased for each test within a test set (Table 3 and Figure 6).

Table 3. Braking longitudinal traction coefficient for Team O'Neil.

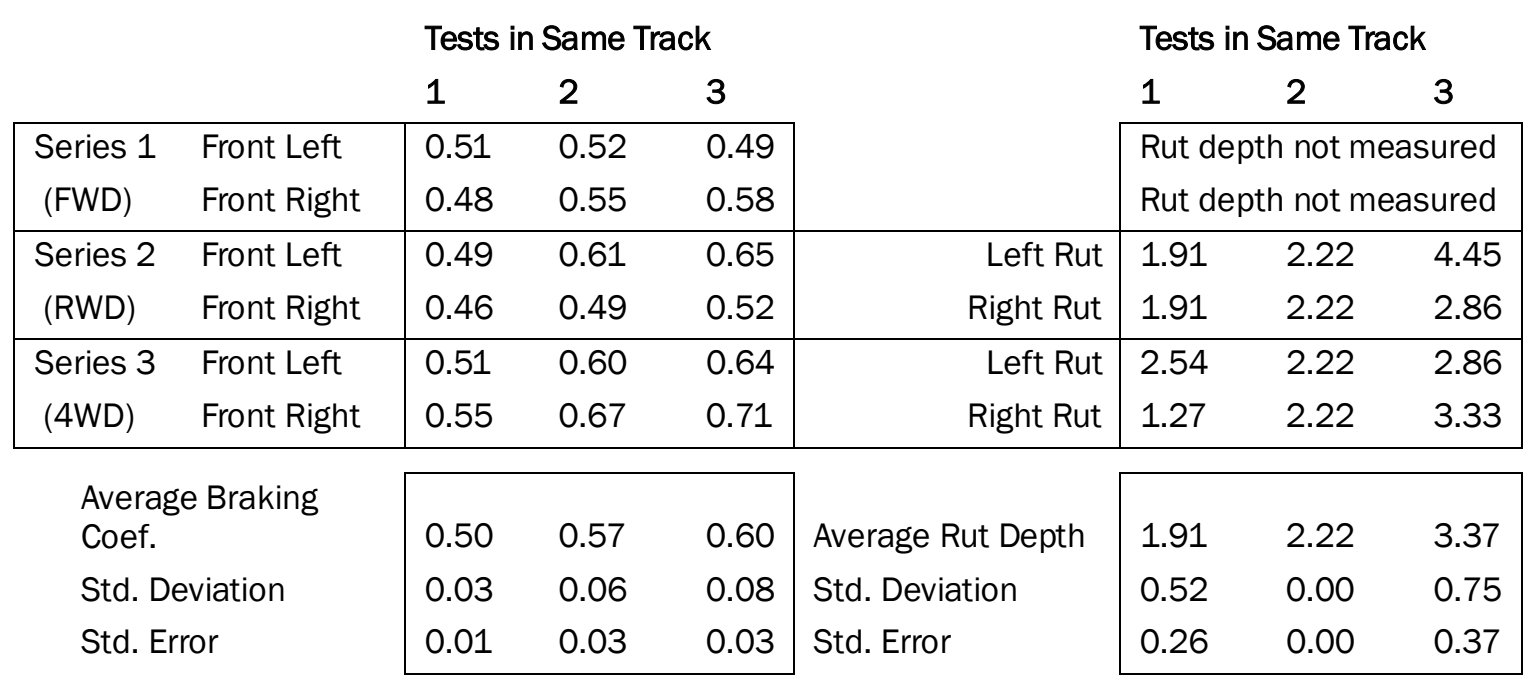



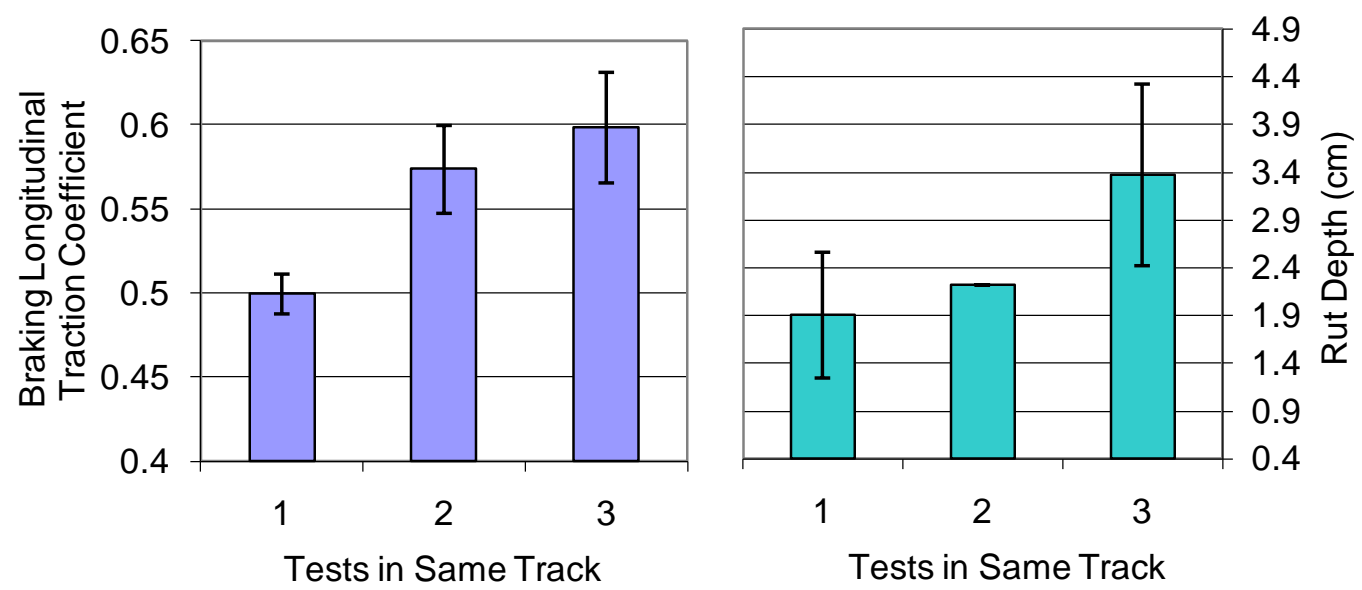

Figure 6. Straight-line braking results at Team O'Neil showing on average increasing longitudinal traction (left) and rut depths (right) through three series of three tests in the same path.

\section{MPG tests (21 July 2009)}

Straight-line braking tests at MPG were performed with the FWD Focus and the CIV in RWD. Weather conditions were generally dry with a few periods of very light rain, which did not appear to affect the pea stone. Spray paint, chalk, and sand were applied to the gravel surface to track particle motions. Thin spray-paint lines of alternating colors oriented perpendicular to the travel path were used to paint the pea-stone particles and track the motion of those large particles (Figure 7). Patches of sand and chalk in the vehicle's path were used to determine the motion of finer particles, which were absent from the pea-stone material.

During the SLB maneuver, coarse and fine particles were transported forward to approximately a 45-degree angle from the track (Figure 7). Largegrained particles (spray-painted stone) were transported up to $8.2 \mathrm{~m}$ from their original location. Fine-grained material (chalk) was transported up to $1 \mathrm{~m}$. Sand particles were pushed forward along the base of the rut approximately $1.5 \mathrm{~m}$. Sand particles appeared to remain within the rut. Rut depths ranged from 2.5 to $4.4 \mathrm{~cm}$, depending on the depth of the original surface material. After the first run, the majority of the pea stone was pushed away, leaving the recycled asphalt layer exposed. Ruts did not get deeper with additional runs. The slope of the sides of the rut walls ranged from 24 to 28 degrees from horizontal. The angle on the outside of the rut walls was shallower and ranged from 10 to 13 degrees (Figure 7). 


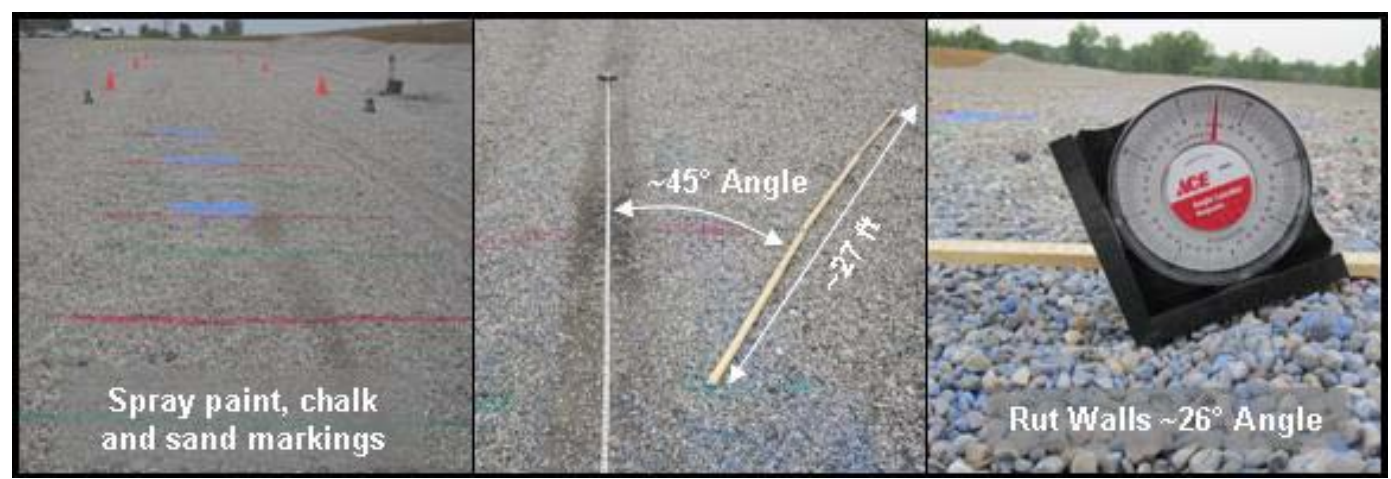

Figure 7. Straight-line braking tests at MPG showing the surface marking, typical spray pattern, and rut wall angles.

For the Focus, longitudinal deceleration is used as a proxy for the longitudinal traction coefficient. Generally, the braking traction (or deceleration) increased with successive passes although there are inconsistencies with this and the change is small (Table 4 and Figure 8). The fifth test for the Focus also showed a lower longitudinal deceleration than the first four. Multiple factors could cause this difference, including gravel material sloughing back into the rut from the rut walls, a slightly different vehicle path, or the precision of the longitudinal traction coefficient and deceleration measurement was insufficient and all measurements could be considered the same value. More data collection is required to determine if the trend is statistically significant.

Table 4. CIV straight-line braking results from MPG.

\begin{tabular}{l|lll|}
\multicolumn{1}{c}{} & \multicolumn{3}{l}{ Tests in Same Track } \\
& $\mathbf{1}$ & $\mathbf{2}$ & $\mathbf{3}$ \\
\hline Front Left & 0.72 & 0.67 & 0.78 \\
Front Right & 0.86 & 0.85 & 0.95 \\
\hline Average Braking Coef. & 0.79 & 0.76 & 0.86 \\
Std. Deviation & 0.09 & 0.13 & 0.12 \\
Std. Error & 0.07 & 0.09 & 0.09 \\
\hline Long. Accel. & -0.61 & -0.59 & -0.63 \\
\hline
\end{tabular}



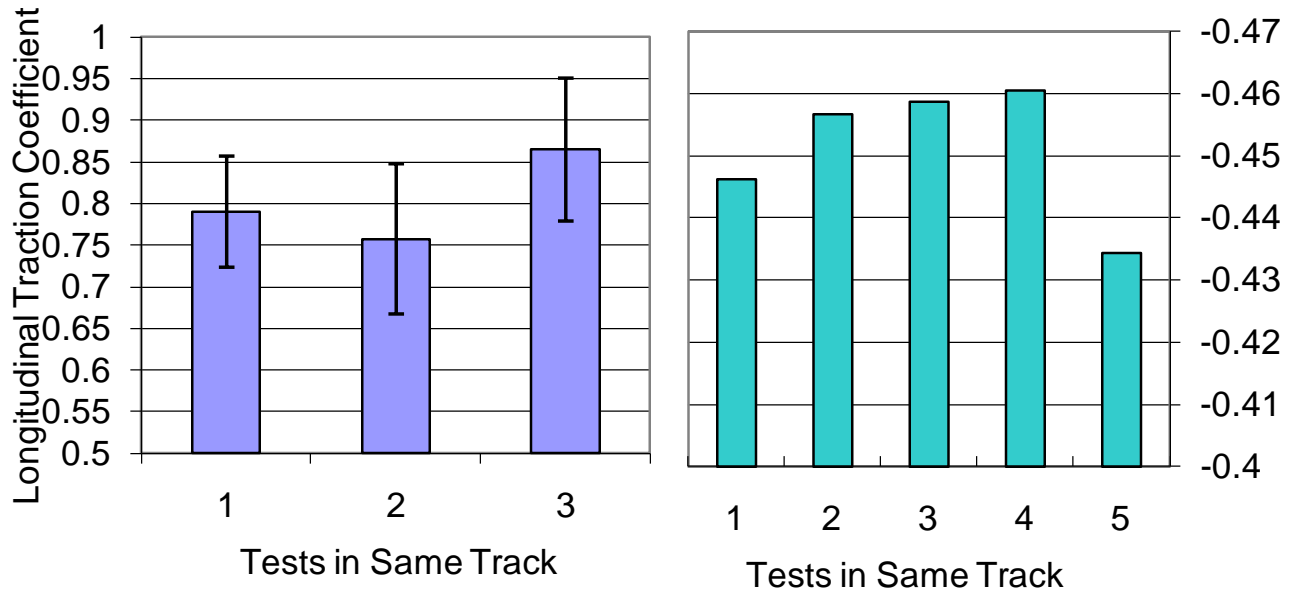

Figure 8. MPG SLB: Longitudinal traction coefficient for the CIV (left) and longitudinal acceleration for the Focus (right), both showing a general trend towards increasing surface traction over successive tests (although not statistically significant).

\section{Hard-turn testing}

Hard-turn tests involved the vehicle traveling at a constant speed of approximately $48 \mathrm{kph}$ and turning hard at a specified location marked with a cone. The driver used either a throttle lift or braking-in-the-turn to induce a controlled skid around the cone. Similar to the SLB tests, three series of hard-turn tests were conducted: initial proof of concept at Team O'Neil under dry conditions, and multiple turns as part of a slalom course at Team O'Neil and MPG. Table 5 summarizes the hard-turn experiments.

Table 5. Hard-turn testing summary.

\begin{tabular}{|l|l|l|l|l|}
\hline Date & Location & Test & $\begin{array}{l}\text { Vehicle (Drive } \\
\text { Configuration) }\end{array}$ & $\begin{array}{l}\text { Surface } \\
\text { Condition }\end{array}$ \\
\hline 5 May 2009 & Team O'Neil & Single Hard-turn & Focus (FWD) & Dry \\
\hline 29 June 2009 & Team O'Neil & $\begin{array}{l}\text { Hard-Turn on } \\
\text { Slalom Course }\end{array}$ & Explorer (RWD) & Wet \\
\hline 23 July 2009 & MPG & $\begin{array}{l}\text { Hard-Turn on } \\
\text { Slalom Course }\end{array}$ & $\begin{array}{l}\text { CIV (RWD) and } \\
\text { Explorer (RWD } \\
\text { and 4WD) }\end{array}$ & Damp \\
\hline
\end{tabular}

\section{Team 0'Neil Proof of concept (5 May 2009)}

Proof of concept tests at Team O'Neil were conducted under dry conditions in the FWD Ford Focus. A $0.6 \mathrm{~m}$ by $1.8 \mathrm{~m}$ multilayer test patch was constructed in the same manner as for the SLB proof of concept test with a thin layer of red chalk located approximately 2.5 to $4 \mathrm{~cm}$ below the surface 
covered with the gravel surface material and a thin layer of blue chalk on top. A hard turn around a cone was performed at approximately $48 \mathrm{kph}$ causing the vehicle's rear tires to pass through the patch while in a controlled sideways skid.

During the first experiment, blue chalk was sprayed to the outside of the corner and behind the vehicle, but the red chalk patch was not excavated. The second experiment was a much sharper turn. Again, material was sprayed to the outside of the corner. After the second experiment, some red chalk was showing at the base of the patch, indicating that 2.5 to $4 \mathrm{~cm}$ of material was excavated by the skidding tire (Figure 9). Additionally, red-chalk-coated particles were thrown to the outside of the corner up to approximately $10.7 \mathrm{~m}$ from the patch.

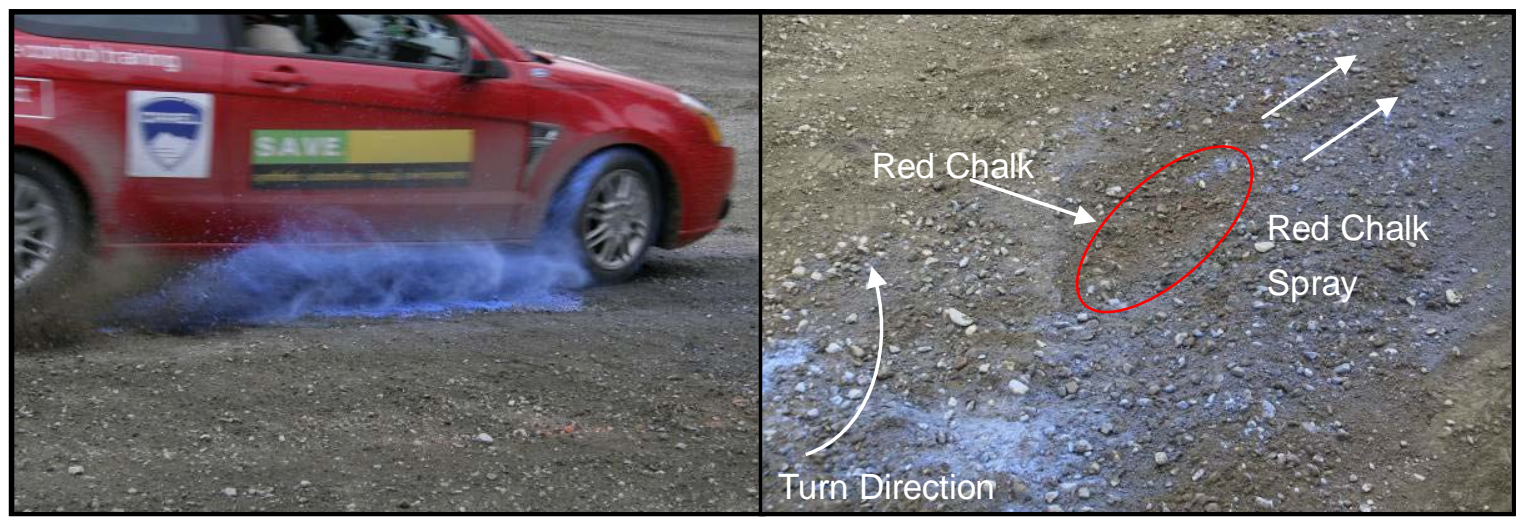

Figure 9. Hard turn tests performed at Team O'Neil under dry conditions showing fine particle spray from the upper surface (left) and excavation down to a depth of 2.5 to $4 \mathrm{~cm}$ indicated by exposed red chalk(right).

\section{Team 0'Neil tests (29 June 2009)}

The hard-turn tests conducted at Team O'Neil occurred during the same rain storm described previously. Hard-turn tests were performed using the Explorer in RWD and were conducted as part of a modified slalom course. Chalk, sand, and spray paint marked the surface for tracking particle motion. Due to the weather conditions and an extremely wet surface, however, spray paint was the only useful particle marker. Particle motion was video recorded and photographed for each test. Again multiple tests were completed in the same path to observe how the surface developed over time.

Unlike straight-line braking, hard-turn tests are much more difficult to repeat in the exact same path; vehicle paths ranged up to approximately

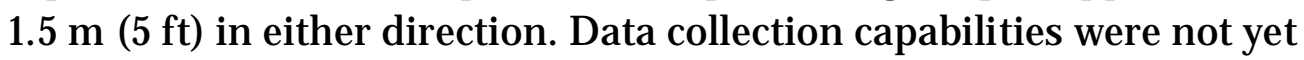


fully developed on the Explorer, so vehicle dynamics information was collected for only two of the five tests. The average maximum lateral acceleration at the painted turn was 0.405 and $0.536 \mathrm{G}$ for the first and second measured tests, respectively. The entrance speed for the first test was $48 \mathrm{kph}$ while the entrance speed for the second test was $64 \mathrm{kph}$ (Table 6).

Table 6. Explorer results from Team O'Neil hard-turn tests.

\begin{tabular}{lll|} 
& \multicolumn{3}{l}{ Instrumented Tests in Same Track } \\
& $\mathbf{1}$ & $\mathbf{2}$ \\
Lateral Acceleration & $0.405 \mathrm{G}$ & $0.536 \mathrm{G}$ \\
Entrance Speed & $48 \mathrm{kph}$ & $64 \mathrm{kph}$ \\
\hline
\end{tabular}

Observations of particle motion showed fine material being thrown primarily by the rear tires to the outside of the corner approximately $6 \mathrm{~m}$ from the traveled path regardless of drive configuration. As a result of repetitive vehicle maneuvers and saturated surface conditions, the fine material mixed with water to form a mud slurry. The courser material was typically transported several centimeters from the tire path (up to $15 \mathrm{~cm}$ ) (Figure 10, left). Images from the tests show a gradation of the material picked up by the vehicle, coarsest at the base and fining upward with increased height (Figure 10, right). Unexpectedly, a viscous layer consisting of mixed fines and course material that formed as a result of the vehicle maneuvers was, in many cases, neatly folded over (Figure 10, center). In these cases, approximately 2.5 to $4 \mathrm{~cm}$ of material from the tire track was removed and folded on top of the adjacent surface revealing the more competent, less-saturated, solid surface below.

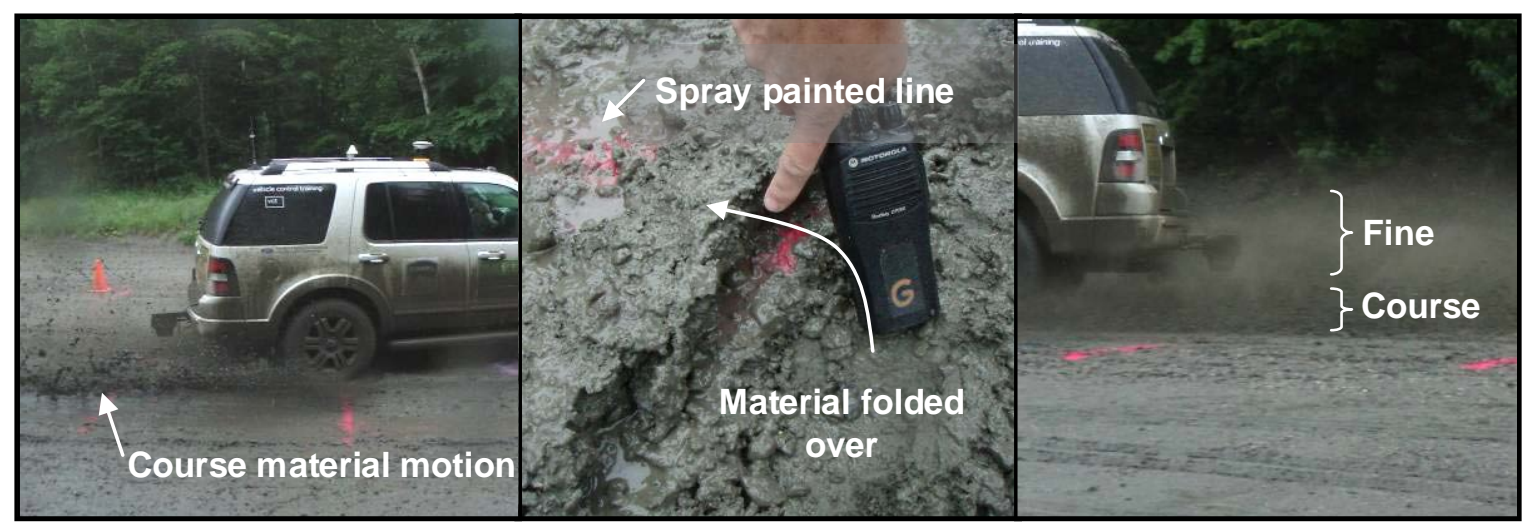

Figure 10. Hard-turn tests at Team O'Neil showing coarse material spray (left), fold-over surface material (center), and gradation in the throw height of course through fine material (right). 


\section{MPG tests (23 July 2009)}

Hard-turn tests were conducted at MPG under slightly moist surface conditions. Professional rally drivers drove the CIV, Focus, and Explorer through a modified slalom course. Spray paint, chalk, and sand were placed at the predicted location of maximum drift. As discussed above, the surface at MPG consisted of 0.6-cm pea stone with very few fine or medium particles. Large particles were spray painted to track their movement. In the absence of fine to medium particles, colored sand and chalk were applied to the surface to assess how those particle sizes might track if they were present. Alternating lines and colors of spray paint and chalk were applied across the vehicle path perpendicular to the vehicle's travel direction (Figure 11, left). Two 0.3 by $0.6 \mathrm{~m}$ patches were made; the bottom layer was sand covered with pea stones and capped with a layer of chalk (Figure 11, center and right). These patches were placed in the tire track of the inside and outside wheels. As with the other tests, particle motion was video recorded and photographed for each test, measurements of particle motion were obtained, and multiple tests were completed in the same path to observe surface development over time.

Observations of particle motion showed that material was primarily thrown to the outside of the turn, mainly by the rear tires, regardless of drive configuration. Large particles were thrown to approximately $0.9 \mathrm{~m}$. Smaller chalk particles were thrown a slightly shorter distance of $0.76 \mathrm{~m}$ (Figure 11). After four passes, the inside corner rut depths were approximately $2.0 \mathrm{~cm}$ and outside rut depths were approximately $3.0 \mathrm{~cm}$. No distinct trend in the maximum lateral coefficient collected from the CIV

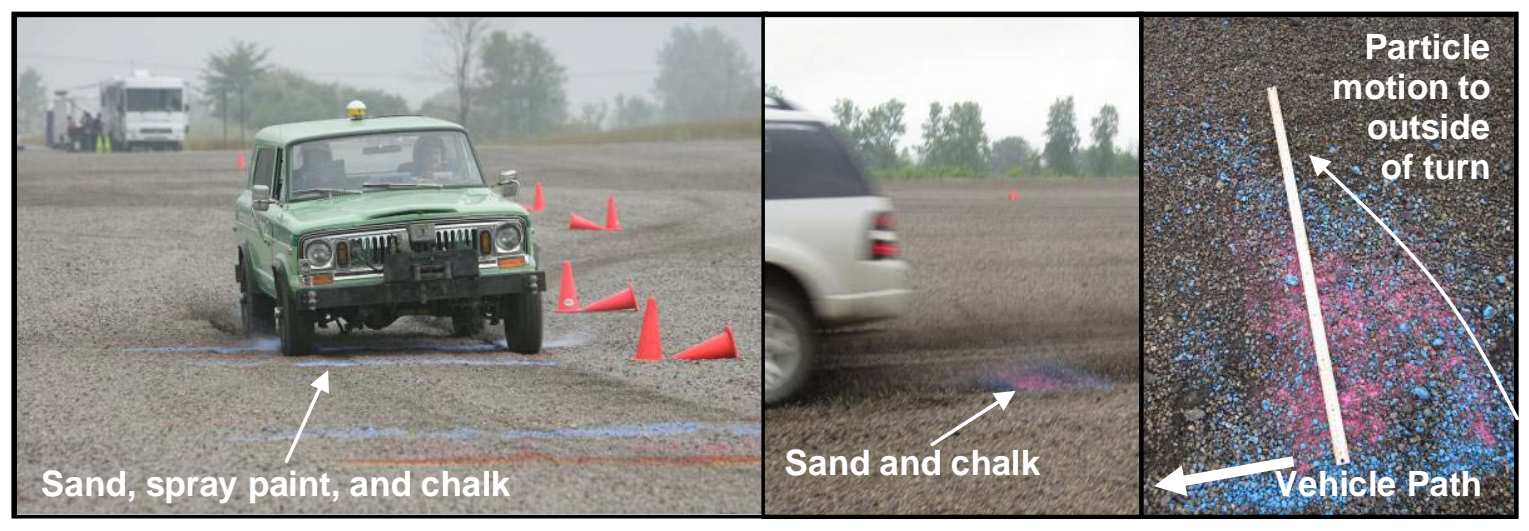

Figure 11. MPG hard-turn tests showing the CIV traveling through the painted section (left), the Explorer traveling through a marked section to determine direction of particle throw (center), and particles thrown to the outside of the corner as a result of drifting through the section with a meter stick (right). 
was observed in the course of the four successive runs in the same track (Figure 12). The maximum lateral accelerations (CIV) for the four tests ranged from 0.43 to $0.53 \mathrm{G}$ and also showed no distinct trend. While no distinct trend is observed in the results, the first test had a slightly lower acceleration and traction coefficient than the remaining tests.

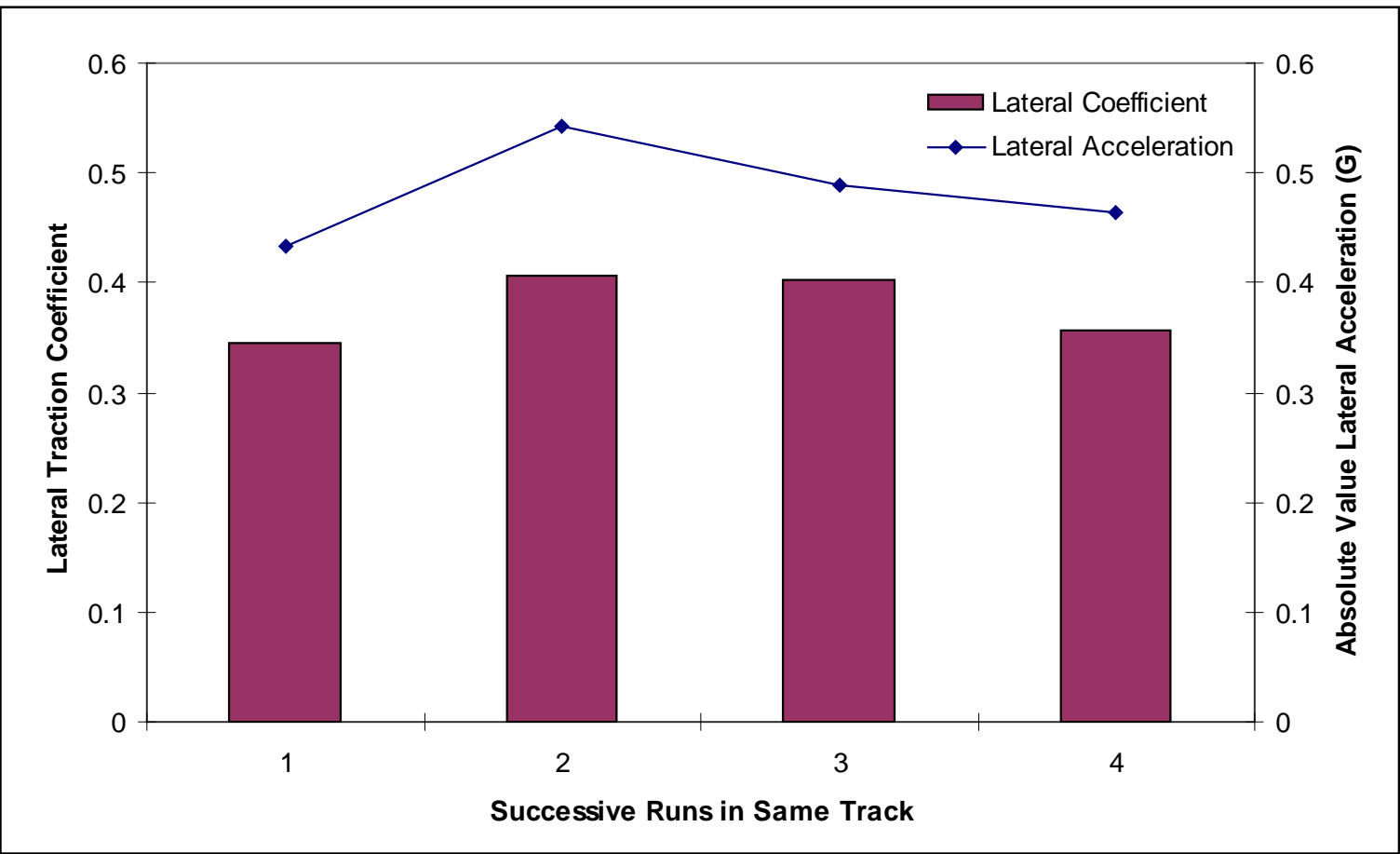

Figure 12. Lateral traction coefficient and lateral acceleration for hard-turn tests in the CIV at MPG shows no distinct trend in either traction or lateral acceleration through successive runs in a similar path.

\section{Degraded surface traction tests}

To further assess the impact of high speed on loose surfaces, longitudinal surface traction tests were performed on both the Team O'Neil and MPG surfaces. For the Team O'Neil wet day and MPG, after a full day of testing, including significantly more high-speed tests than described in this study, additional longitudinal traction tests were performed on the degraded surface. The tests were performed in an area where a significant buildup of loose material occurred and in the adjacent location where the loose material had been scraped away. Here, we refer to the layer where material had been scraped away as the competent layer, meaning a stronger layer that is more difficult to deform. Figure 13 shows the results of the traction tests. Longitudinal traction measurements in the competent layer were $0.74 \pm 0.01$ and $0.68 \pm 0.02$ for Team O'Neil and MPG, respectively. Longitudinal traction measurements were also obtained in the loose material 


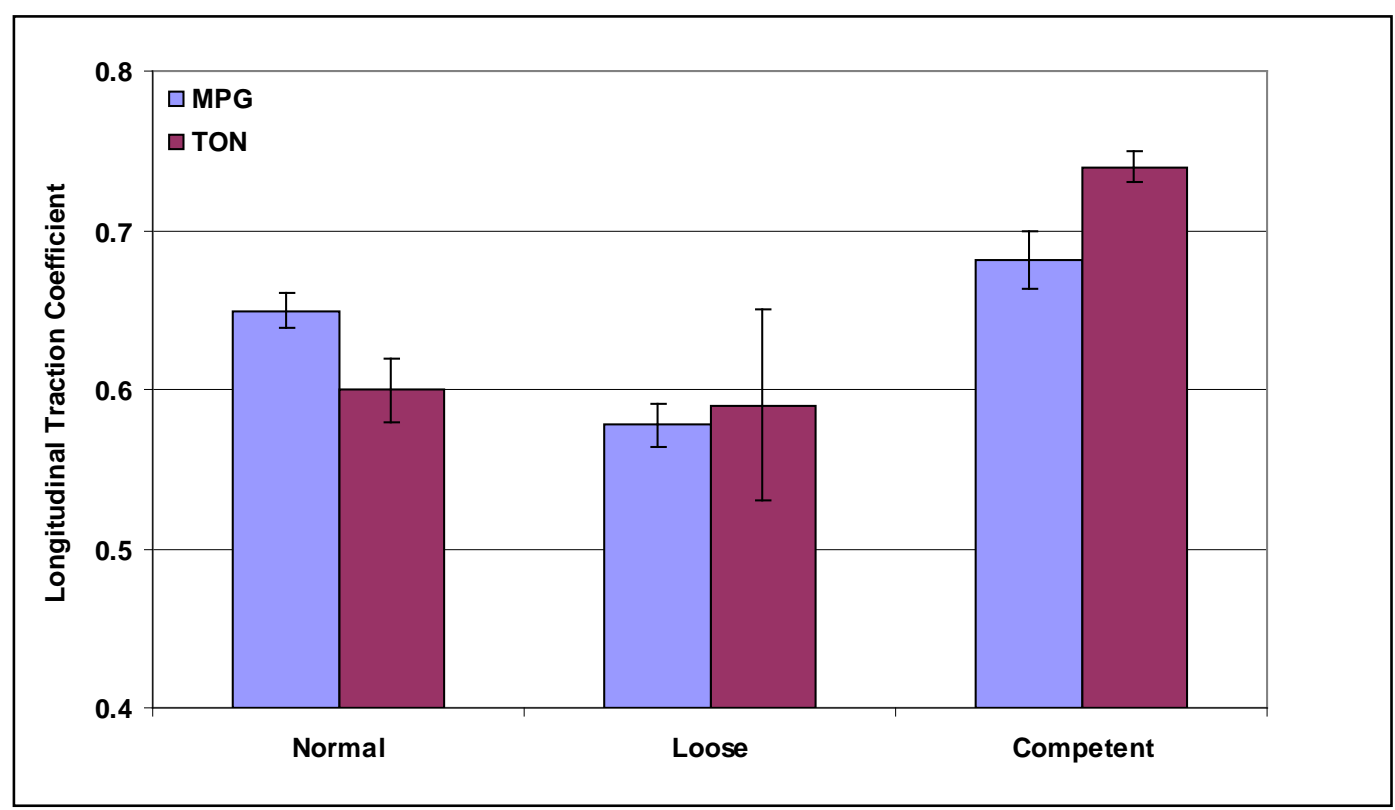

Figure 13. Longitudinal traction coefficient for a normal driving surface, loose surface (a surface of loose material pushed to the side as a result of maneuvers), and competent surface (typically surface below the normal surface after loose material has been removed due to maneuvers).

that accumulates due to high-speed maneuvers and is typically adjacent to the competent layer: $0.59 \pm 0.06$ and $0.56 \pm 0.01$ for Team O’Neil and MPG, respectively.

Additionally, rolling resistance measurements were conducted in an area of significantly deep pea stone (over $20 \mathrm{~cm}$ ) at MPG. The average rolling resistance in that area was 0.16 , an order of magnitude greater than the typical driving surface. While these areas were not created by buildup of loose material due to high-speed maneuvers, the rolling resistance value shows the increase that could be expected with extreme buildup of material. Material buildup at MPG reached up to $10 \mathrm{~cm}$ in areas of intense, repetitive hard turns. 


\section{Discussion}

\section{Straight-line braking}

A common rally technique for negotiating a sharp turn when the driver is entering at excessive speeds is called a trail brake. This maneuver consists of a hard SLB followed by an easing of the brakes as the wheel is turned in the desired direction of travel and ending with the application of the throttle to accelerate out of the turn. To maintain traction on the braking portion of the turn, rally drivers often describe locking up the brakes to scrub off the upper loose surface to reveal a more tractive surface below. The SLB tests performed at Team O'Neil confirm the technique described by rally drivers. As successive tests were conducted, the traction in the travel path increased. Additionally, the rut depth increased, confirming the relationship between increased traction and the removal of the looser surface material in the traveled path. The largest traction increase came between the first and second tests of a series. This is likely due to the vehicle scraping off that upper loose layer, revealing a more competent surface. As additional layers are removed, the increase in traction is not as notable. At some point after more than three tests, it is probable that little additional material would be removed and the traction between tests would no longer increase. Straight-line braking tests at MPG did not show a significant trend. This difference is likely due to the "artificial" gravel surface. The longitudinal traction coefficient for the first test on the surface prior to the removal of any loose material is similar to traction on asphalt (Baumeister 1978). Thus an increase in traction from that already high level is unrealistic.

\section{Hard turns}

As rally drivers enter a turn, they will assess the road surface looking for the area that may have the best traction and avoiding areas of extremely loose material. The hard-turn tests conducted at both Team O'Neil and MPG showed that, as a result of hard turns, surface material is scraped off and typically thrown by the skidding tire to the outside of the turn. However, the data do not show this removal of loose material significantly affecting the lateral traction coefficient or lateral acceleration at the corner. This result is most likely because, while the material is being thrown to the outside of a turn, it is being thrown into the tire track of the outside tire 
(Figure 11). Moreover, it is difficult even for the best drivers to replicate the exact same turning path at $48 \mathrm{kph}$. Thus, on the following tests, the driver may be driving on the material kicked loose from the prior test so that little change in the lateral tractive force would be observed. While our tests were designed to simplify the maneuver, thereby reducing the number of factors influencing the results, there may still be too many variables present to fully understand the data. A longer series of tests at multiple speeds may yield more insight into changes in the driving surface as a result of hard turns.

\section{Traction and rolling resistance}

Traction tests at MPG and Team O'Neil demonstrated significant modifications to the road surface as a result of high-speed maneuvers on loose surfaces. After successive turns along a similar path, material was thrown to the outside of the corner. This material built up over the course of the testing and had lower traction than the normal surface.

At MPG this buildup was much more noticeable, likely due to the artificial gravel surface and lack of fine material to act as a binder. At MPG the loose surface consisted of up to $10 \mathrm{~cm}$ of loose pea stone. At Team O'Neil the loose surface held more fines; therefore, it was more tightly bound, giving it a higher traction.

As surface material is removed, a competent layer is exposed. This competent layer likely consisted of the more compacted layer below the normal surface layer at Team O'Neil. At MPG this layer was the lower recycled asphalt substrate. In both cases, longitudinal traction was better in the competent layer than either the normal or loose surfaces. The increase in traction must either occur as a result of higher speeds or more repetitions since no significant increase in traction was observed in the controlled hard-turn testing. Rolling resistance tests at MPG showed that rolling resistance increases greatly in areas where significant loose material exists. 


\section{Conclusions}

Observations of particle motion as a result of high-speed, rally-style maneuvers on loose surfaces show that particles can be transported many car lengths away from the traveled path. As vehicles continue to follow the same path, particles are scraped off and build up on the adjacent section of roadway. Traction along the section seeing the most high-speed vehicle traffic - and thus significant surface alteration-is improved from the surface prior to trafficking and is significantly better than the adjacent surface where the loose material is accumulated. This study quantifies anecdotal observations of rally-car drivers that reading the driving surface is critical to maintaining traction at high speeds and thereby control of the vehicle. We plan to use the results of this study to develop a training program for driving at high speed on loose surfaces using a vehicle simulator. As the simulator becomes more sophisticated, features will be added that will modify the traction on specific sections of road based on the maneuvers of previous simulator drivers, thereby allowing the road surface to develop in a realistic manner over time.

The SLB tests validated the anecdotal descriptions of the driving surface by rally-car drivers. Traction improved in the traveled path as the driver scraped off the upper loose layer of material revealing a more competent surface below. This was demonstrated in the SLB tests and the traction tests completed after a day of high-speed maneuvers. In contrast, no notable pattern was discernable during the hard-turn tests. This implies that, to significantly affect surface conditions, either substantially more maneuvers than the five completed in the hard-turn tests or substantially higher speeds are required.

Several additional series of tests should be completed to improve understanding of the impacts of high-speed maneuvers on loose-surface materials. Additional repetitions of straight-line braking in the same travel path would indicate when the traction is no longer improved by additional passes of the vehicle. Layered patch surface tests in dry conditions with an instrumented vehicle would provide additional insight into the depth of penetration of the tires into the surface. A longer series of hard-turn tests at more aggressive, higher speeds may capture the dynamic surface changes as a result of surface material being scraped away. And finally, 
after any series of rally-style maneuvers, traction and rolling resistance should be measured in both the competent and loose-surface layers. 


\section{References}

American Society for Testing and Materials (ASTM). 2002. D 5874-02, Standard Test Method for Determination of the Impact Value (IV) of a Soil, West Conshohocken, PA: ASTM.

Baumeister, T., E. Avallone, and T. Baumeister. 1978. Marks' Standard Handbook for Mechanical Engineers Eighth Edition. New York, NY: McGraw-Hill Book Company.

Blaisdell, G. L. 1983. The CRREL instrumented vehicle: Hardware and software. Special Report 833. Hanover, NH: Cold Regions Research and Engineering Laboratory.

Clegg, B. 1980. An impact soil tester as an alternative to California bearing ratio. Proc., 3rd Australian-New Zealand (ANZ) Geomechanics Conference, Wellington, New Zealand, 1: 225- 230.

Coutermarsh, B., and S. Shoop. 2010. Lateral Force versus Tire Angle Measurements for Various Field Conditions. SAE Technical Paper 2010-01-0374. Warrendale, PA: SAE International.

Coutermarsh, B., and S. Shoop. 2009. Loose surface vehicle dynamics and their relationship with driver inputs. 11th European Regional Conference of the International Society for TerrainVehicle Systems - Bremen, Germany, October 5-8 2009.

Coutermarsh, B., and S. Shoop. 2008. Tire slip-angle force measurements on winter surfaces. J ournal of Terramechanics 46(4): 157- 163.

National Climactic Data Center (NCDC) Climate Data Online (2010). Hourly Precipitation Data St. J ohnsbury Vermont. COOP-ID 437054 for J uly 29, 2009, Asheville, NC.

Shoop, S., B. Coutermarsh, and J. Stanley. 2010. High-Speed Vehicle Operations on Gravel Surfaces. SAE Technical Paper 2010-01-0640. Warrendale, PA: SAE International.

Shoop, S., and B. Coutermarsh. 2006. Tire cornering force test method for winter surfaces. SAE Paper No. 2006-01-1627. In Steering \& Suspension Technology and Tire \& Wheel Technology, Special Publication 2019.

Webster, S. L., R. H. Grau, and T. P. Williams. 1992. Description and application of Dual Mass Dynamic Cone Penetrometer. Final Report. Vicksburg, MS: Waterways Experiment Station. 


\section{Appendix: Soil Strength Tests}

\section{Strength tests: Team 0’Neil, Dalton, NH (29 Jun 09)}

Soil Strength: Soil strength measurements were conducted in two selected areas (SLB and Skid Pad/hard turn), using a dynamic cone penetrometer (DCP), a Loadman, standard Clegg Impact Hammer-(CIH), and Light Weight Clegg Impact Hammer (CIHL).

The DCP is used to quantify the bearing capacity of the soil and is translated into soil strength in terms of California bearing ratio (CBR) values ranging from 1 to 100 percent (where the 100 percent value is representative of the CBR of crushed limestone gravel). The DCP consists of a steel rod with a $1.6-\mathrm{cm}$-diameter shaft and a $60^{\circ}$ cone. As the whole device is held vertically, the cone penetrates into the soil by the drop of a 8-kg (17.6lb) hammer from a repetitive set distance. The number of hammer blows is counted, and penetration depth is measured for each set of hammer blows. $\mathrm{CBR}$ values are calculated using a relationship developed by Webster et al. 1992:

$$
C B R \%=\frac{292}{\text { DCPindex }}
$$

where CBR is the soil strength, and DCP index is the average penetration caused by one hammer blow. One DCP profile was conducted at each selected area. On the SLB area, a depth of $350 \mathrm{~mm}$ (14 in.) was tested. On the skid pad area, a depth of $460 \mathrm{~mm}$ (18 in.) was tested. 


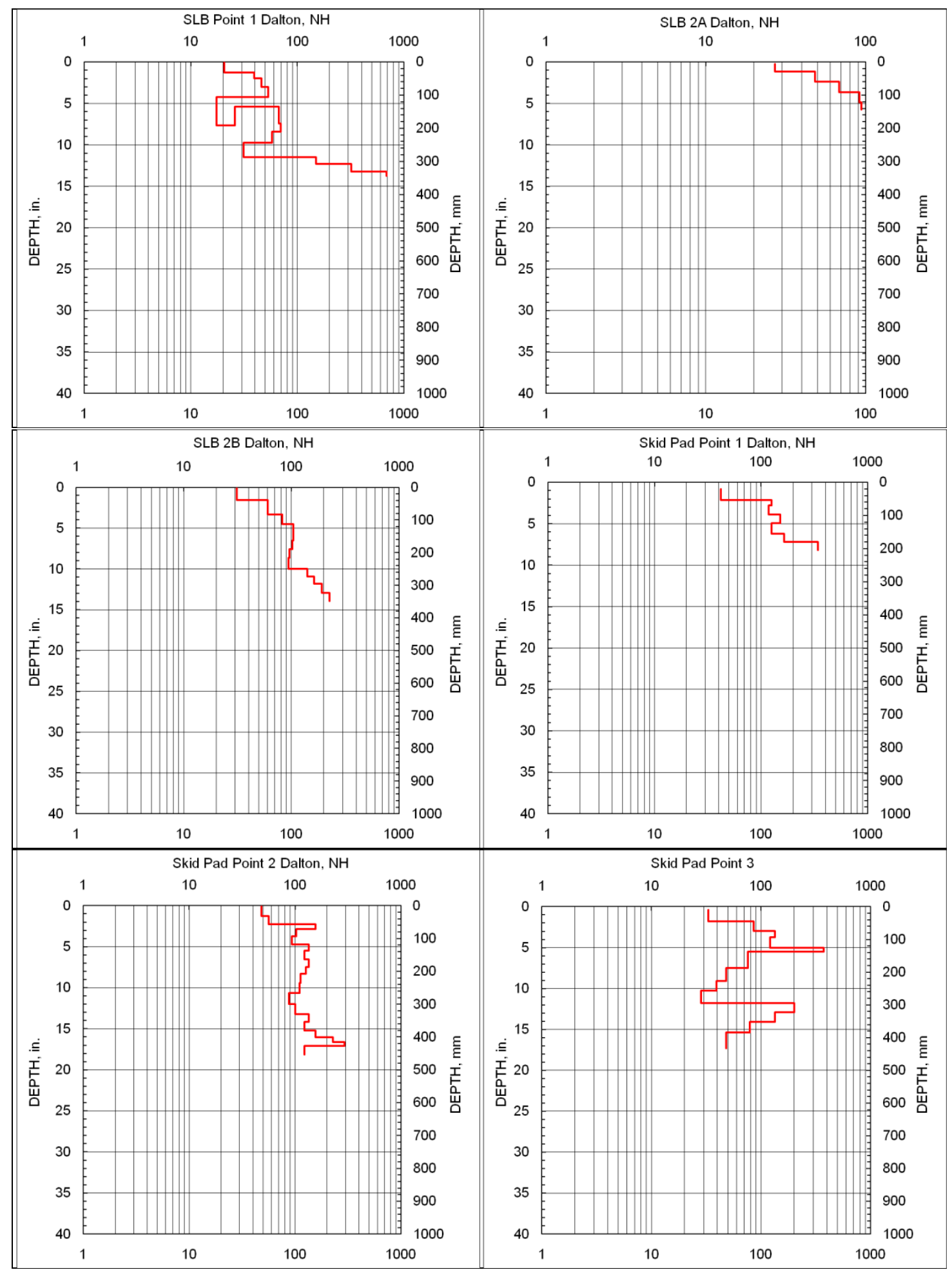

Figure A1. DCP Profiles for Team O'Neil, 29 June 2009.

While the DCP yields a profile of the soil strength, the Loadman and both Clegg impact hammers give a composite strength measure of the surface soil layer. The Loadman is a portable device used to measure the modulus 
of the soil surface layer. The zone of influence for the measurement is approximately the top $152 \mathrm{~mm}$ (6 in.) of soil. The device design uses an accelerometer to measure the acceleration and associated deflection caused by a specific weight falling from a given height. The results are reported as a maximum deflection, the calculated elastic (E) modulus, the length of the loading impulse, the percentage of the rebound deflection compared to the maximum deflection, and a compaction ratio (the ratio of the second and subsequent deflections compared to the first measured deflection at that measurement location). For this study, we are primarily interested in the E modulus. Readings were conducted on selected areas for comparison. Five to six drops were used at each measurement location.

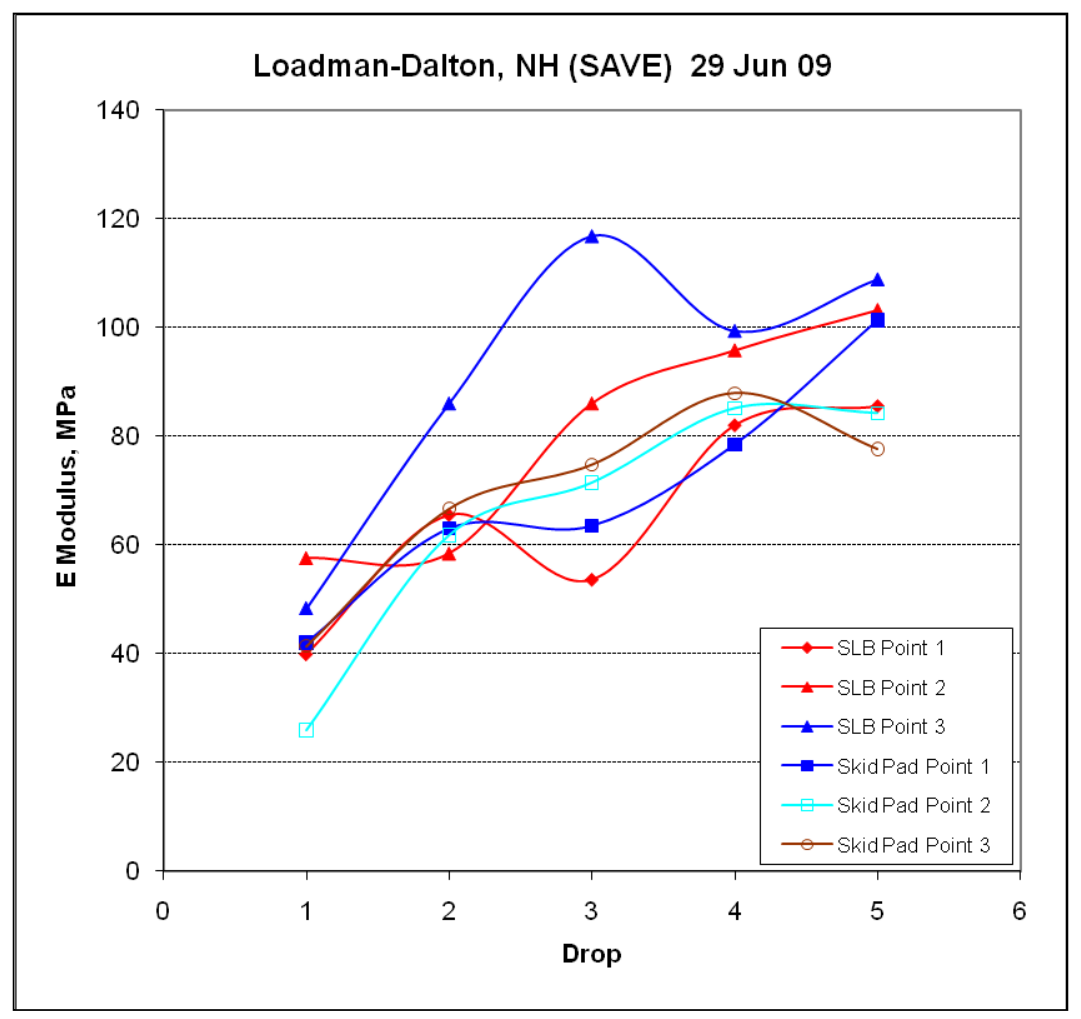

Figure A2. Loadman data for Team O'Neil, 29 June 2009.

Surface soil strength was also measured using the CIH and the CIHL. Testing was performed with a cylindrical mass hammer that was dropped within a guide tube from a set height. The hammer was dropped four times at each location, and the readings were recorded for each drop. The hammer was equipped with an accelerometer that measured the peak deceleration on impact. The readings were displayed as Clegg Impact Value (CIV), and the fourth reading was converted to CBR (ASTM 2002 D 5874; Clegg 1980). The CIH used a $4.5 \mathrm{~kg}$ (9.9 lb) hammer mass, and the CIHL used a 
$0.5 \mathrm{~kg}(1.1 \mathrm{lb})$ mass. The standard Clegg was used for all testing areas. Three sets of readings were taken at the SLB area, three sets of readings at the hard-turn area, and readings in the "cheese" (loose material adjacent to the wheel path termed "cheese" by rally-car drivers) in the area of the hard turns. An average value was calculated for each area. CBR can be estimated using the relationships developed for $\mathrm{CIH}$ and CIHL readings:

Standard Clegg reading conversion to CBR:

$$
\mathrm{CBR}=(0.24(\mathrm{CIV})+1)^{2}
$$

Light Clegg conversion to CBR:

$$
\mathrm{CBR}=(0.0121(\mathrm{CIVL}))^{2}+(0.1005(\mathrm{CIVL}))
$$

where (CIV) is the fourth drop impact value of the standard Clegg reading and (CIVL) is the fourth drop impact value of the light Clegg reading

\begin{tabular}{|c|c|c|c|c|c|c|c|c|}
\hline \multicolumn{5}{|l|}{ Light Clegg Hammer $0.5 \mathrm{~kg}$} & \multicolumn{2}{|c|}{$\begin{array}{l}\text { Calculated } \\
\text { Modulus }\end{array}$} & & \multirow{2}{*}{$\begin{array}{c}\text { AVG } \\
\text { Modulus } \\
\text { (MPa) }\end{array}$} \\
\hline Location & Reading 1 & Reading 2 & Reading 3 & Reading 4 & CBR & (Mpa) & CBR & \\
\hline SLB Pt 1] & 5.5 & 5.5 & 7.8 & 8.2 & 1 & 6 & & \\
\hline SLB Pt 2 & 5.3 & 11.8 & 16.9 & 17.1 & 2 & 26 & 1 & 14 \\
\hline SLB Pt 3 & 2.6 & 9 & 10.7 & 10.7 & 1 & 10 & & \\
\hline Skid Pad Pt 1 & 5.3 & 8.5 & 11.4 & 15.2 & 2 & 20 & & \\
\hline Skid Pad Pt 2 & 5.2 & 12.4 & 14.3 & 16.9 & 2 & 25 & 2 & 24 \\
\hline Skid Pad Pt 3 & 7.9 & 10.6 & 14.7 & 17.6 & 2 & 27 & & \\
\hline Cones $5 \& 6$ (Hard-turn) & 4.4 & 4.3 & 3.8 & 6 & 1 & 3 & 1 & 3 \\
\hline Wheel Path (Hard-turn) & 11.1 & 13.7 & 13.7 & 13.7 & 1 & 17 & & \\
\hline & 26.1 & 30.9 & 31.2 & 31.2 & 3 & 86 & 2 & 51 \\
\hline Cheese (Hard-turn) & 0.8 & 1.6 & 2 & 2.1 & 0 & 0 & 0 & 0 \\
\hline
\end{tabular}

Table A1. Clegg data for Team O'Neil, 29 June 2009.

\begin{tabular}{|c|c|c|c|c|c|c|c|c|}
\hline \multicolumn{9}{|l|}{ Location } \\
\hline SLB Pt 1 & 8.0 & 18.0 & 22.0 & 22.0 & 39 & 43 & & \\
\hline SLB Pt 2 & 6.0 & 22.0 & 23.0 & 24.0 & 46 & 51 & 46 & 51 \\
\hline SLB Pt 3 & 18.0 & 25.0 & 26.0 & 26.0 & 52 & 59 & & \\
\hline Skid Pad Pt 1 & 15.0 & 22.0 & 27.0 & 31.0 & 55 & 85 & & \\
\hline Skid Pad Pt 2 & 6.0 & 14.0 & 23.0 & 26.0 & 39 & 59 & 44 & 68 \\
\hline Skid Pad Pt 3 & 6.0 & 14.0 & 23.0 & 26.0 & 39 & 59 & & \\
\hline
\end{tabular}


In summary, the calculated CBR values for the DCP, in all selected areas, exceeded 100. Due to heavy rains, the Clegg readings were taken in saturated soil conditions. CBR values of 1 or 2 were achieved for the CIHL, and $\mathrm{CBR}$ values for the $\mathrm{CIH}$ were 44 and 46 . The standard Clegg was able to reach a higher $\mathrm{CBR}$ due to its ability to penetrate through the cheese. The penetration of the accelerometer was on average $19 \mathrm{~mm}$ (3/4 in). Loadman E modulus results were $65 \mathrm{MPa}$. Laboratory moisture results on the soil showed SLB area and hard-turn area at approximately $12 \%$ moisture and the cheese at $16 \%$ moisture. According to samples obtained in December 2008 of the stock pile of crush-and-run gravel used to maintain the driving surface, $12 \%$ of the material contained particles in the clay and silt size range. By comparison, recent samples gathered resulted in $20 \%$ of particles in the silt and clay size range, due to the amount of rain and heavy traffic. A typical crush-and-run gravel would contain no more than $10 \%$ in the silt and clay size range. The soil was classified as a silty sand (SM). Atterberg tests showed the liquid limit (where a material would behave as a liquid) of the recent samples to be $16 \%$ moisture content. The plastic index was "no plasticity." Thus the surface material on the day of testing behaved on the edge between a liquid and semi-solid state. 


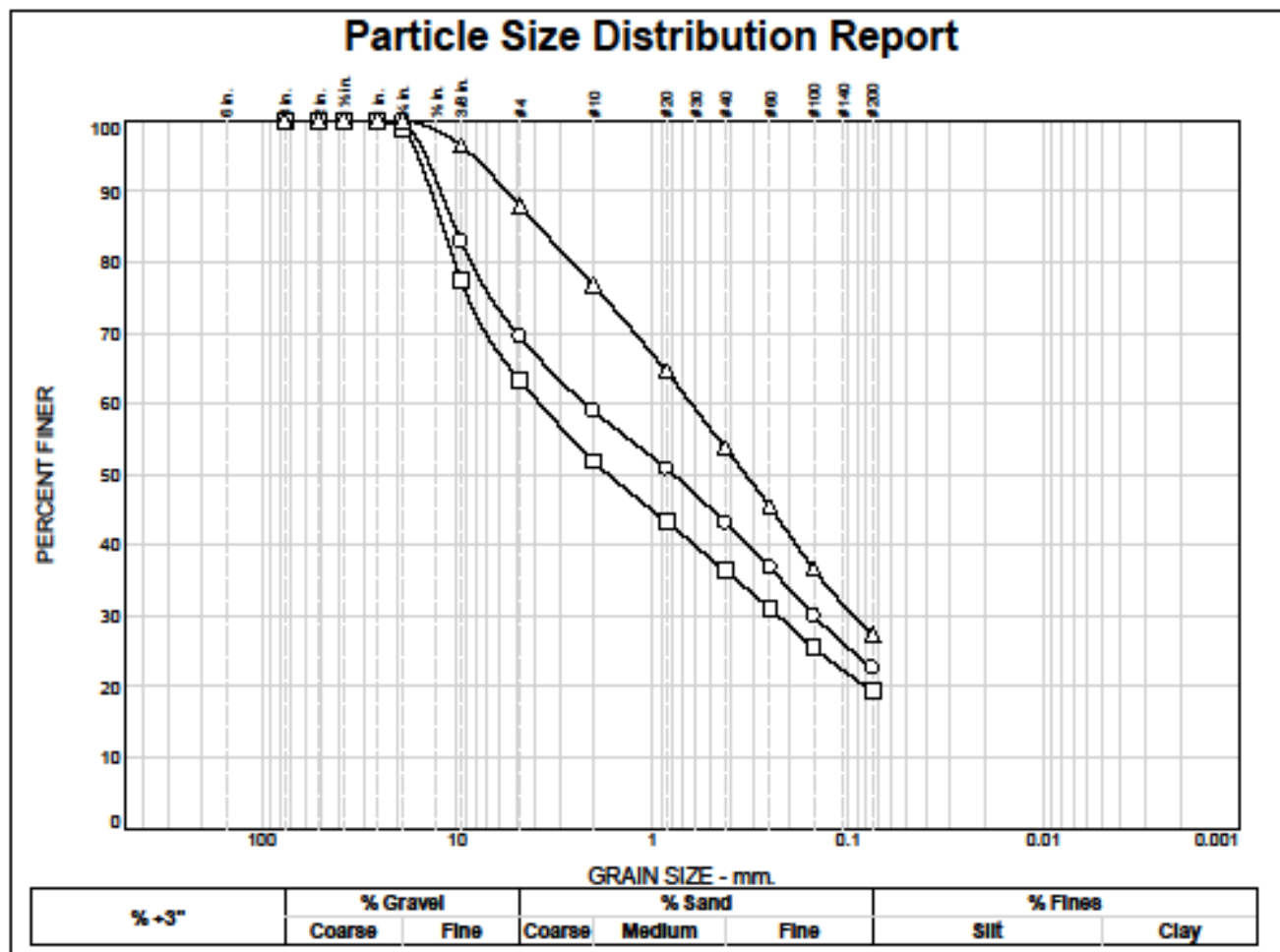

\begin{tabular}{|c|c|c|c|c|c|}
\hline \multicolumn{6}{|c|}{ MATERIAL DATA } \\
\hline SYMBOL & SOURCE & $\begin{array}{l}\text { SAMPLE } \\
\text { NO. }\end{array}$ & $\begin{array}{c}\text { DEPTH } \\
\text { (ft.).) }\end{array}$ & Material Decoription & usce \\
\hline \multirow[t]{2}{*}{0} & & SLB sample & $0-2$ inchs & silty sand with gravel containing small cobbles and stones and & SM \\
\hline & & & & pebbles & \\
\hline \multirow[t]{2}{*}{$\square$} & & Skid Pad & $0-2$ inchs & silty sand with gravel containing small cobbles and stones and & SM \\
\hline & & sample & & pebbles Geryish white in color & \\
\hline \multirow[t]{2}{*}{$\Delta$} & & Cheese & $0-2$ inches & silty sand containing small stones and pebbles greyish white in color & SM \\
\hline & & sample & & & \\
\hline & & & & & \\
\hline & & & & & \\
\hline & & & & & \\
\hline
\end{tabular}

\begin{tabular}{|c||ll||}
\hline US ARMY - CRREL & $\begin{array}{l}\text { Client: Sally Shoop } \\
\text { Project: S.A.V. program }\end{array}$ \\
Hanover, New Hampshire & Project No.: & Figure \\
\hline \hline
\end{tabular}

Tested By: Chris Berini

Checked By: СMB

Figure A3. Grain size analysis for Team O'Neil, 29 June 2009.

\section{Strength tests: MPG, Romeo, MI (20 July 2009)}

Soil Strength: Soil strength measurements were conducted throughout the testing area. Figure A4 shows the four corners of the test area and the Global Positioning System (GPS) locations and names of the sampling sites. 


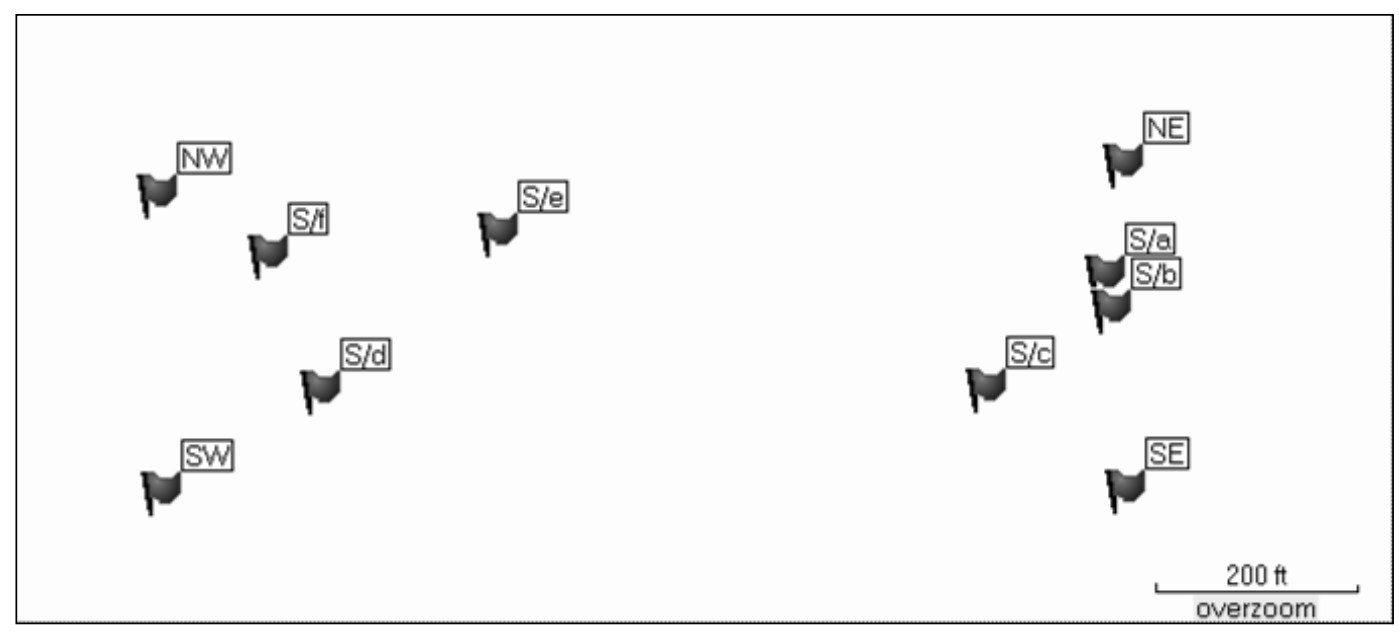

Figure A4. GPS locations of the four corners of the testing area and the locations of soil strength measurements.

The DCP is used to quantify the bearing capacity of the soil and is translated into soil strength in terms of CBR values ranging from 1 to 100 percent (where 100 percent is representative of the CBR of crushed limestone gravel). The DCP consists of a steel rod with a 1.6-cm-diameter shaft and a $60^{\circ}$ cone. As the whole device is held vertically, the cone penetrates into the soil by the drop of a $8 \mathrm{~kg}(17.6 \mathrm{lb})$ hammer from a repetitive set distance. The number of hammer blows is counted, and penetration depth is measured for each set of hammer blows. CBR values are calculated using a relationship (Equation A1) developed by Webster et al. (1992):

$$
C B R \%=\frac{292}{\text { DCPindex }}
$$

where CBR is the soil strength, and DCP index is the average penetration caused by one hammer blow. Five DCP profiles were conducted: three to a depth less than $300 \mathrm{~mm}$ (11.8 in.) and two deeper profiles to a depth greater than $800 \mathrm{~mm}$ (31.5 in.). 


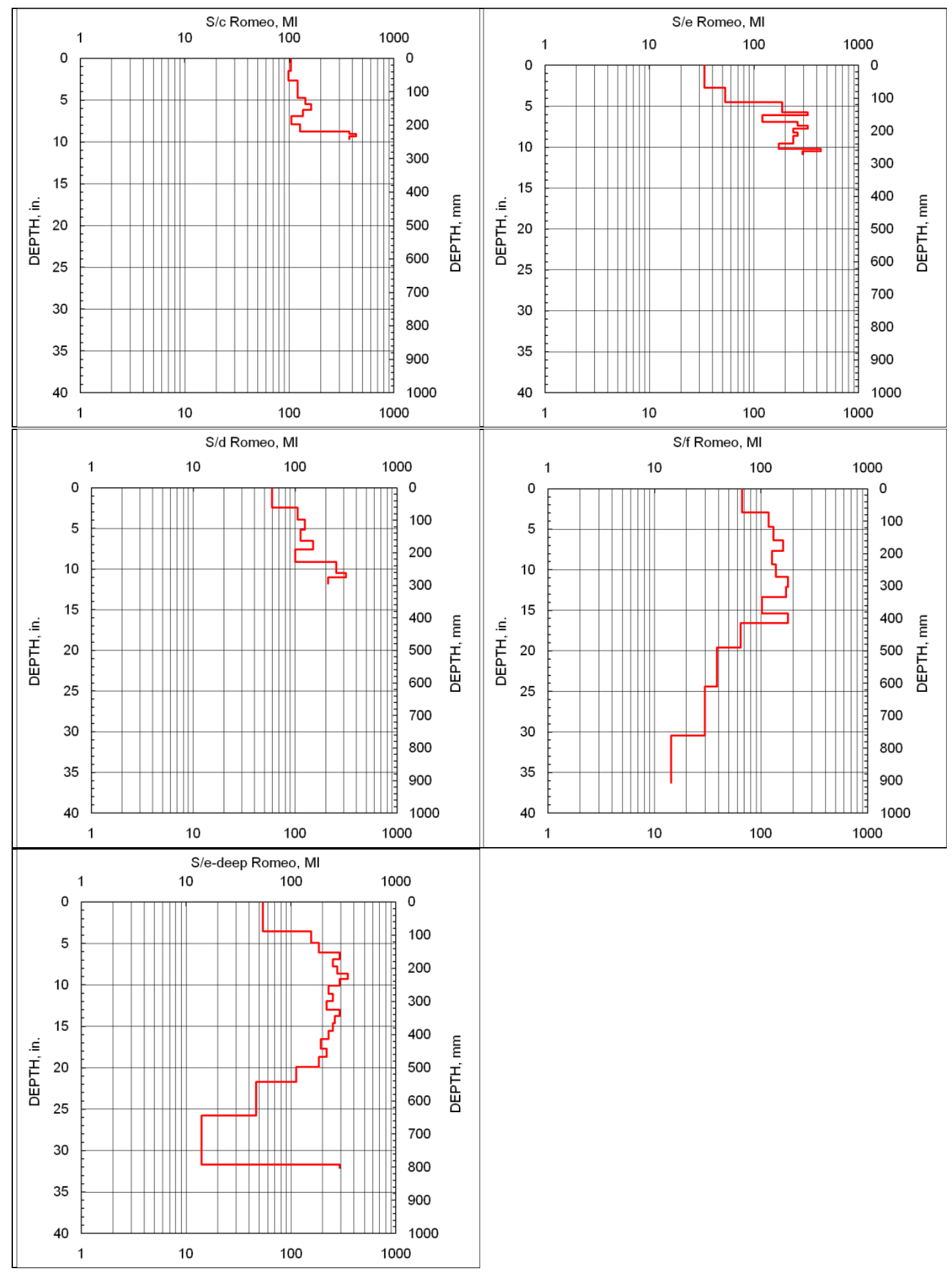

Figure A5. DCP data from Romeo, MI, 20 July 2009. 

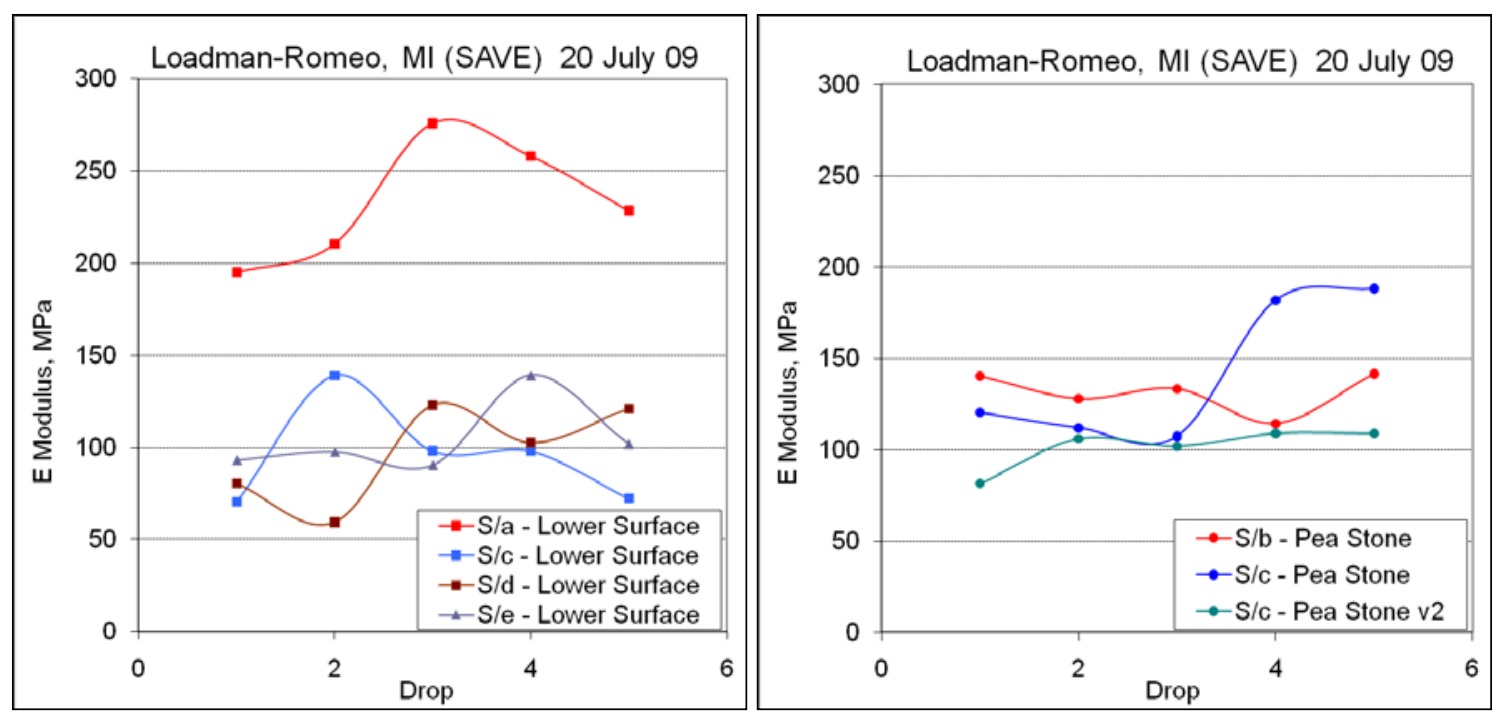

Figure A6. Loadman data for Romeo, MI, 20 July 2009.

Surface soil strength was also measured using the CIH. Its cylindrical mass hammer was dropped within a guide tube from a set height four times at each location. The readings were recorded for each drop. The hammer's accelerometer measured the peak deceleration on impact. The fourth CIV reading was converted to CBR (ASTM 2003 D 5874; Clegg 1980). The CIH with a $4.5 \mathrm{~kg}$ (9.9 lb) hammer mass was used for all testing areas. Five readings were taken from tests performed on the lower layer below the pea stone (the surface pea-stone layer was scraped away by hand), three readings were collected in the cheese, and two were collected in the competent material (lower layer below the pea stone) after the surface material was removed by vehicular motions. An average value was calculated for each area. CBR can be estimated using the relationships developed for the $\mathrm{CIH}$.

Standard Clegg reading conversion to CBR:

$$
\mathrm{CBR}=(0.24(\mathrm{CIV})+1)^{2}
$$

where (CIV) is the fourth drop impact value (standard Clegg reading). 
Table A2. Clegg data from Romeo, MI, 20 July 2009.

\begin{tabular}{|c|c|c|c|c|c|c|c|c|}
\hline \multirow{2}{*}{$\begin{array}{l}\text { Clegg Hammer } 4.5 \mathrm{~kg} \\
\text { Location }\end{array}$} & \multirow[b]{2}{*}{ Reading 1} & \multirow[b]{2}{*}{ Reading 2} & \multirow[b]{2}{*}{ Reading 3} & \multirow[b]{2}{*}{ Reading 4} & \multicolumn{2}{|c|}{ Calculated } & \multirow{2}{*}{$\begin{array}{l}\text { AVG } \\
\text { CBR } \\
\end{array}$} & \multirow{2}{*}{$\begin{array}{c}\text { AVG } \\
\begin{array}{c}\text { Modulus } \\
\text { (MPa) }\end{array}\end{array}$} \\
\hline & & & & & CBR & $\begin{array}{c}\text { Modulus } \\
\text { (MPa) }\end{array}$ & & \\
\hline S/c - lower Level & 33.0 & 43.0 & 44.0 & 45.0 & 139 & 178 & & \\
\hline S/c Lower Level v2 & 29.0 & 38.0 & 41.0 & 44.0 & 134 & 170 & 113 & 141 \\
\hline S/d - Lower Level & 26.0 & 36.0 & 36.0 & 38.0 & 102 & 127 & & \\
\hline S/e - Lower Level & 24.0 & 29.0 & 33.0 & 32.0 & 75 & 90 & & \\
\hline $\begin{array}{l}\text { Cheese Slalom } \\
4 \mathrm{~cm} \text { deep }\end{array}$ & 12.0 & 6.0 & 5.0 & 12.0 & 15 & 13 & & \\
\hline $\begin{array}{l}\text { Loose Material Slalom } \\
\text { Turn } 29.5 \mathrm{~cm} \text { deep }\end{array}$ & 0.0 & 4.0 & 4.0 & 5.0 & 5 & 2 & 8 & 5 \\
\hline $\begin{array}{l}\text { Loose Material Slalom } \\
\text { Turn } 2 \text { again } 9.5 \mathrm{~cm} \text { deep }\end{array}$ & 0.0 & 4.0 & 4.0 & 4.0 & 4 & 1 & & \\
\hline $\begin{array}{l}\text { Competent Slalom } \\
\text { Turn } 2\end{array}$ & 17.0 & 24.0 & 28.0 & 30.0 & 67 & 79 & 128 & 163 \\
\hline $\begin{array}{l}\text { Competent Slalom } \\
\text { Entering Turn } 1\end{array}$ & 37.0 & 45.0 & 48.0 & 53.0 & 188 & 247 & & \\
\hline
\end{tabular}

In summary, the calculated CBR values for the DCP, at all sampling locations, exceeded 100. CBRs for the standard Clegg ranged from 75 to 139 for the lower layer after surface material was removed by hand, 4 through 15 for the loose material layer, and 67 and 188 for the two readings on competent material (surface material removed by vehicle motions). Loadman results for the competent layer showed two different curves. One had a high E modulus of $233 \mathrm{MPa}$ while the others were $99 \mathrm{MPa}$. This is likely due to the difficulty in finding a flat surface on the dense lower layer below without disturbing it. The average pea-stone E modulus was $125 \mathrm{MPa}$.

Sieve tests were not performed on the collected material as the surface

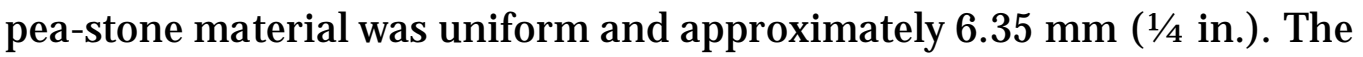
lower surface was a recycled asphalt surface. 


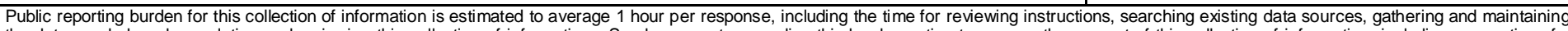

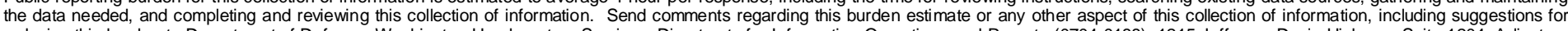

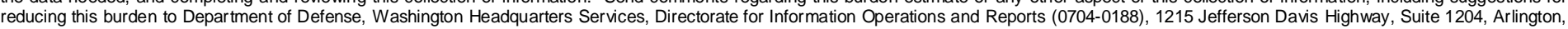

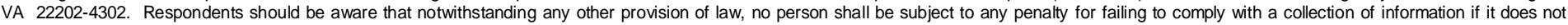
display a currently valid OMB control number. PLEASE DO NOT RETURN YOUR FORM TO THE ABOVE ADDRESS.
1. REPORT DATE (DD-MM-YYYY)
2. REPORT TYPE
3. DATES COVERED (From - To)

30-11-2010

Final Technical Report

\section{TITLE AND SUBTITLE}

Loose-Surface Tire-Terrain Interaction During High-Speed Maneuvers

5a. CONTRACT NUMBER

5b. GRANT NUMBER

5c. PROGRAM ELEMENT NUMBER

\section{AUTHOR(S)}

Nicole L. Buck, Barry A. Coutermarsh, and Sally A. Shoop

5d. PROJECT NUMBER

5e. TASK NUMBER

5f. WORK UNIT NUMBER

\section{PERFORMING ORGANIZATION NAME(S) AND ADDRESS(ES)}

8. PERFORMING ORGANIZATION REPORT NUMBER

Cold Regions Research and Engineering Research Laboratory

U.S. Army Engineer Research and Development Center

ERDC/CRREL TR-10-11

प 2 Lyme Road

Hanover, NH 03755-1290

\section{SPONSORING I MONITORING AGENCY NAME(S) AND ADDRESS(ES)}

10. SPONSOR/MONITOR'S ACRONYM(S)

Headquarters

U.S. Army Corps of Engineers

Washington, DC 20314-1000

11. SPONSOR/MONITOR'S REPORT NUMBER(S)

\section{DISTRIBUTION / AVAILABILITY STATEMENT}

Approved for public release; distribution is unlimited.

\section{SUPPLEMENT ARY NOTES}

\section{ABSTRACT}

For many years, rally-car drivers have been training military Special Forces in driving techniques that allow them to maintain high speeds on loose surfaces. The Cold Regions Research and Engineering Laboratory has been working with rally-car drivers to gain a more complete understanding of their driving techniques and their knowledge of driving on loose surfaces. This study was designed to quantify anecdotal descriptions of dynamic changes in the road surface as a result of successive high-speed maneuvers on a loosesurface roadway. The two primary maneuvers tested both involve a controlled skid on unpaved surfaces: the straight-line brake and high-speed hard turn. Multiple tests of each maneuver were completed over the same section of roadway on two different types of loose surface. Test observations showed that, as a vehicle traverses a section of roadway in a controlled skid, the tires remove loose material and transport the material to a new location, thereby changing the tractive characteristics of the roadway. This change is amplified as successive vehicles traverse the same path. A significant increase in the surface traction coefficient is observed where material has been removed from the original surface, and a decrease in surface traction is observed where loose material has built up on the original surface.

\begin{tabular}{|ll}
\hline 15. SUBJECT TERMS & Vehicle mobility \\
& Terrain dynamics \\
& Surface traction
\end{tabular}

\section{SECURITY CLASSIFICATION OF:}

a. REPORT

U b. ABSTRACT

U

\section{c. THIS PAGE}

17. LIMITATION OF ABSTRACT

U
18. NUMBER

44 19a. NAME OF RESPONSIBLE PERSON

19b. TELEPHONE NUMBER (include area code) 